\title{
Metal Material, Properties and Design Methods of Porous Biomedical Scaffolds for Additive Manufacturing: A Review
}

\author{
Yuting $\mathrm{Lv}^{1,2}$, Binghao Wang ${ }^{1}$, Guohao $\mathrm{Liu}^{1}$, Yujin Tang ${ }^{3 *}$, Eryi Lu ${ }^{4 *}$, Kegong Xie ${ }^{3}$, \\ Changgong Lan ${ }^{3}$, Jia Liü*, Zhenbo Qin ${ }^{5}$ and Liqiang Wang ${ }^{2}$
}

${ }^{1}$ College of Mechanical and Electronic Engineering, Shandong University of Science and Technology, Qingdao, China, ${ }^{2}$ State Key Laboratory of Metal Matrix Composites, Shanghai Jiao Tong University, Shanghai, China, ${ }^{3}$ Affiliated Hospital of Youjiang Medical University for Nationalities, Baise, China, ${ }^{4}$ Renji Hospital, Shanghai Jiao Tong University, Shanghai, China, ${ }^{5}$ Tianjin Key Laboratory of Composite and Functional Materials, School of Material Science and Engineering, Tianjin University, Tianjin, China

OPEN ACCESS

Edited by:

João Conde,

New University of Lisbon, Portugal

Reviewed by:

Qiang Chen,

Southeast University, China

Monica Mattioli-Belmonte,

Marche Polytechnic University, Italy

*Correspondence:

Yujin Tang

tangyujin196709@163.com

Eryi Lu

lueryi222@126.com

Jia Liu

liujia0111@live.cn

Specialty section:

This article was submitted to Biomaterials,

a section of the journal

Frontiers in Bioengineering and

Biotechnology

Received: 13 December 2020

Accepted: 23 February 2021

Published: 26 March 2021

Citation:

LV Y, Wang B, Liu G, Tang Y, Lu E, Xie K, Lan C, Liu J, Qin Z and Wang L (2021) Metal Material, Properties and Design Methods of Porous Biomedical Scaffolds for Additive

Manufacturing: A Review.

Front. Bioeng. Biotechnol. 9:641130.

doi: 10.3389/fbioe.2021.641130
Design an implant similar to the human bone is one of the critical problems in bone tissue engineering. Metal porous scaffolds have good prospects in bone tissue replacement due to their matching elastic modulus, better strength, and biocompatibility. However, traditional processing methods are challenging to fabricate scaffolds with a porous structure, limiting the development of porous scaffolds. With the advancement of additive manufacturing (AM) and computer-aided technologies, the development of porous metal scaffolds also ushers in unprecedented opportunities. In recent years, many new metal materials and innovative design methods are used to fabricate porous scaffolds with excellent mechanical properties and biocompatibility. This article reviews the research progress of porous metal scaffolds, and introduces the AM technologies used in porous metal scaffolds. Then the applications of different metal materials in bone scaffolds are summarized, and the advantages and limitations of various scaffold design methods are discussed. Finally, we look forward to the development prospects of AM in porous metal scaffolds.

Keywords: metal material, additive manufacturing, porous scaffold, design, bone tissue engineering

\section{INTRODUCTION}

Bone defects caused by pathologies such as fracture, bone tumor, or external trauma are among the main problems in clinical treatment (Moiduddin et al., 2017). Autologous bone transplantation is considered to be a good choice, but the mismatched performance of different bone sites and the limited number of useful bone grafts limit the application of autologous bone transplantation (Henkel et al., 2013). In contrast, allogeneic bone transplantation has an obvious risk of immune rejection and infection, which affects bone formation and is prone to bone resorption. Therefore, it is ideal to seek natural bone replacement for bone transplantation in orthopedics.

As an alternative material, porous metal scaffolds avoid a series of adverse reactions in natural bone grafting and have gradually attracted researchers' attention. To simulate the mechanical properties and biocompatibility of real bone, porous metal scaffolds not only have interconnected 
porous structures but also have good mechanical properties and biocompatibility (Li et al., 2020a). Mechanical properties mainly include better yield strength, matching elastic modulus, and better fatigue strength (Yuan et al., 2019). Common biomedical metal materials such as $\mathrm{Ti}$ and $\mathrm{Ti}$ alloys can completely meet bone implants needs in terms of strength. Nevertheless, the elastic modulus of dense metals is much greater than that of human bones, which is prone to bone resorption and leads to bone loosening in the human body (Bundy, 2008). The porous scaffolds can obtain matching elastic modulus with human bone by adjusting the pore size and porosity (Kelly et al., 2019), and at the same time have better yield and fatigue strength (Chen et al., 2018). Porous metal scaffolds should also have good biocompatibility, which not only can promote cell attachment, growth, proliferation, and differentiation, but also facilitates the transport of nutrients and metabolic wastes (Little et al., 2011; Saint-Pastou Terrier and Gasque, 2017).

Traditional processing methods are challenging to prepare porous metal scaffolds with complex structures, while additive manufacturing (AM) technology can prepare the scaffolds with controllable structures, shape, and properties (Wang et al., 2020a). Thus AM is one of the most effective methods to prepare porous metal scaffolds. The design of porous metal scaffolds is another crucial problem because scaffold features such as unit type, pore size, porosity, and distribution have significantly influence on their mechanical properties and biocompatibility. Therefore, this article introduces the AM technologies for preparing metal scaffolds and summaries the research progress in relative metal materials, including non-biodegradable metals (Ti alloys, Ta alloy, and stainless steel), and biodegradable metals (Fe, Mg alloy, and $\mathrm{Zn}$ alloy). Besides, we review the structural characteristics of porous metal scaffolds and their design methods in detail, and evaluate the advantages and limitations of these methods. Finally, we prospect the future development direction of bone scaffolds.

\section{BASIC REQUIREMENTS FOR METAL POROUS SCAFFOLDS}

For metal implants, the elastic modulus is a very important mechanical performance (Ngo et al., 2018). Large elastic modulus differences between the implants and the bone tissue can result in "stress shielding" effect, which will gradually trigger the loosening of the implant, finally leading to the failure of implant. As known to all, solid metals has much higher elastic modulus than bone tissue (Li et al., 2020a). Obviously, the solid metals are not suitable to use as implants. Thus porous structures were designed in order to reduce the elastic modulus of the solid metals. Metal porous implants should be non-toxic, non-rejection, and non-allergenic, which requires us to select suitable metal as raw material (Roseti et al., 2017). Good biocompatibility is also reflected in the reasonable porous shape and distribution, which can promote the adhesion and growth of bone tissue cells (Shor et al., 2007). In addition, metal porous scaffolds should have good wear and corrosion resistance. Worse wear resistance can cause loosening of the scaffolds, and metal particles caused by wear or metal ions formed due to the corrosion effect can lead to tissue reactions and lesions (Wang et al., 2020a). Furthermore, the scaffolds should have good machinability, and the structures can be obtained using existing processing technologies.

\section{ADDITIVE MANUFACTURING TECHNOLOGY}

Additive manufacturing (AM) technologies, also known as $3 \mathrm{D}$ printing, attracts extensive attention in the fabrication of biomedical implants due to their capability of manufacturing porous scaffolds with irregular shapes (Chen et al., 2020b). AM prepares products by layer-by-layer stacking method, which divides into the following three steps. Firstly, the entity model is established by commercial software such as UG, Pro/Engineer, SolidWorks, and Materialise 3-Matic, etc. Secondly, the model is imported into slicing software for slicing and layering. Finally, the layered file is imported into a $3 \mathrm{D}$ printer, and the parts are formed layer by layer from bottom to top. At present, the AM technologies suitable for preparing porous metal scaffolds mainly divides into two categories: powder bed fusion technology (PBF) and directional deposition technology (DED) (Chen et al., 2020a). Compared with DED, PBF can prepare the parts with better manufacturing accuracy and surface quality and are more prevalent in the biomedical field. Therefore, this article focuses on powder bed fusion technologies, including selective laser sintering (SLS), selective laser melting (SLM), and electron beam melting (EBM) (Chen et al., 2020b). The differences in these AM technologies are summarized, as shown in Table $\mathbf{1 .}$

\section{Selective Laser Sintering (SLS) and Selective Laser Melting (SLM)}

Figure 1A show the schematic diagram of SLS. SLS uses a laser as an energy source to sinter the powder materials (SzymczykZiółkowska et al., 2020). After melting one layer, the equipment descends to fabrication platform and raises the powder delivery platform. Then the roller rolls out powders on the fabrication platform, and a new layer of sintering begins. This process is repeated until entirely formation of the part. When using SLS, prepared material need introduce binder materials (alloys with a low melting point) to reduce the melting point, promoting sintering (Lee et al., 2017). SLS can prepare a variety of materials such as polymers (Goodridge et al., 2012), metals and alloys (Bae et al., 2014), etc. but it is challenging to prepare metal materials with a high melting points.

Selective laser melting is developed based on SLS technology, and its principles are the same. Nevertheless, powder material and the bonding mechanisms in the two technologies are different. In SLS technology, the powder materials are heated to partly melt by laser beams instead of completely melting (Bose et al., 2018). Powders with a low melting points are used as binders for bonding high melting point metals (Qu, 2020). Compared with SLS, the laser of SLM has higher energy (Dogan et al., 2020), which can completely melt the powder. Thus it can prepare metals or alloys with a high melting points. The parts prepared by SLM have higher dimensional accuracy and density, 
and their mechanical properties are comparable to those of forged one. Due to the high sintering temperature, the powder sintering needs to be performed under the protection of inert gas to prevent metal oxidation (Wang et al., 2017).

Selective laser melting technology also has shortcomings. The surface of parts prepared by SLM can adhere to some particles that do not melt completely (Zadpoor, 2019), resulting in its high surface roughness. It is necessary to smooth the surface by sandblasting or chemical corrosion (Ahmadi et al., 2019; Zadpoor, 2019). Besides, when the SLM is used to process brittle materials, residual stresses are easily generated inside the parts during the cooling process. Thus it is often necessary to adopt isobaric sintering or heat treatment to eliminate residual stress (Fang et al., 2020).

\section{Electron Beam Melting (EBM)}

Electron beam melting, like SLS and SLM, is a powder bed fusion technology (PBF). The significant differences between SLM and EBM are the source of energy, and their energy sources are laser and high-energy, high-speed electron beams, respectively. Figure 1B show the principle of EBM. The electron gun emits electrons, and then the electron beam is accelerated by the heated

TABLE 1 | Summaries of four different additive manufacturing technologies: selective laser sintering (SLS), selective laser melting (SLM), electron beam melting (EBM), and directional deposition technology (DED).

\begin{tabular}{|c|c|c|c|c|c|c|}
\hline Category & Materials & Application & $\begin{array}{l}\text { Resolution } \\
(\mu \mathrm{m})\end{array}$ & Advantages & Disadvantages & References \\
\hline SLS & $\begin{array}{l}\text { Polymers } \\
\text { Metals } \\
\text { Alloys }\end{array}$ & $\begin{array}{l}\text { - Biomedical fabrication } \\
\text { - Shipbuilding } \\
\text { - Auto industry } \\
\text { - Aerospace }\end{array}$ & $76-100$ & $\begin{array}{l}\text { - Superior mechanical } \\
\text { properties } \\
\text { - Complex geometry } \\
\text { - No supporting } \\
\text { - High utilization of powder } \\
\text { Materials }\end{array}$ & $\begin{array}{l}\text { - Low energy efficiency } \\
\text { - Expensive } \\
\text { Low density }\end{array}$ & Chohan et al., 2017; Ngo et al., 2018 \\
\hline SLM & $\begin{array}{l}\text { Metals } \\
\text { Alloys }\end{array}$ & $\begin{array}{l}\text { - Biomedical fabrication } \\
\text { - Shipbuilding } \\
\text { - Auto industry } \\
\text { - Aerospace }\end{array}$ & $80-250$ & $\begin{array}{l}\text { - Superior mechanical } \\
\text { properties } \\
\text { - Complex geometry } \\
\text { - No supporting } \\
\text { - High density }\end{array}$ & $\begin{array}{l}\text { Expensive } \\
\text { - Residual stress } \\
\text { - Rough surface } \\
\text { - Time consuming process }\end{array}$ & Sood et al., 2010; Tofail et al., 2018 \\
\hline EBM & $\begin{array}{l}\text { Metals } \\
\text { Alloys }\end{array}$ & $\begin{array}{l}\text { - Biomedical fabrication } \\
\text { - Shipbuilding } \\
\text { - Auto industry } \\
\text { - Aerospace }\end{array}$ & $50-100$ & $\begin{array}{l}\text { - Superior mechanical } \\
\text { properties } \\
\text { - Complex geometry } \\
\text { - No supporting }\end{array}$ & $\begin{array}{l}\text { Expensive } \\
\text { - Rough surface } \\
\text { - Time consuming process }\end{array}$ & Ngo et al., 2018; Qu, 2020 \\
\hline DED & $\begin{array}{l}\text { Metals } \\
\text { Alloys } \\
\text { Ceramics } \\
\text { Glass } \\
\text { Polymers }\end{array}$ & $\begin{array}{l}\text { - Aerospace } \\
\text { - Repair of bespoke } \\
\text { parts } \\
\text { - Biomedical } \\
\text { application }\end{array}$ & 250 & $\begin{array}{l}\text { Good mechanical } \\
\text { properties } \\
\text { - Rapid cooling rates } \\
\text { - Effective time and cost of } \\
\text { repairs }\end{array}$ & $\begin{array}{l}\text { Low resolution } \\
\text { - Low surface quality } \\
\text { - Producing less complex } \\
\text { - parts }\end{array}$ & Gibson et al., 2015; Mohamed et al., 2015 \\
\hline
\end{tabular}

A

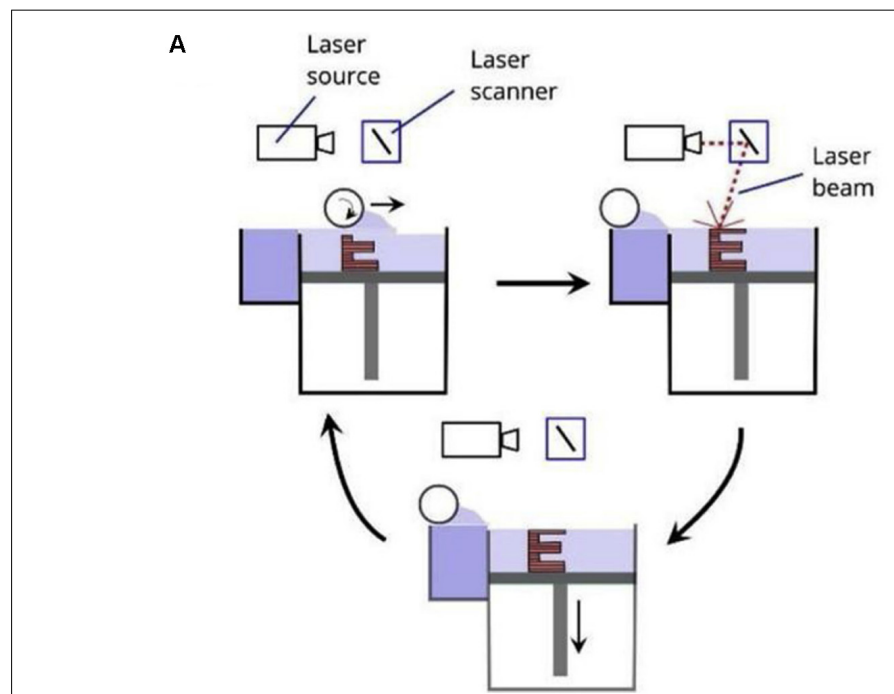

B
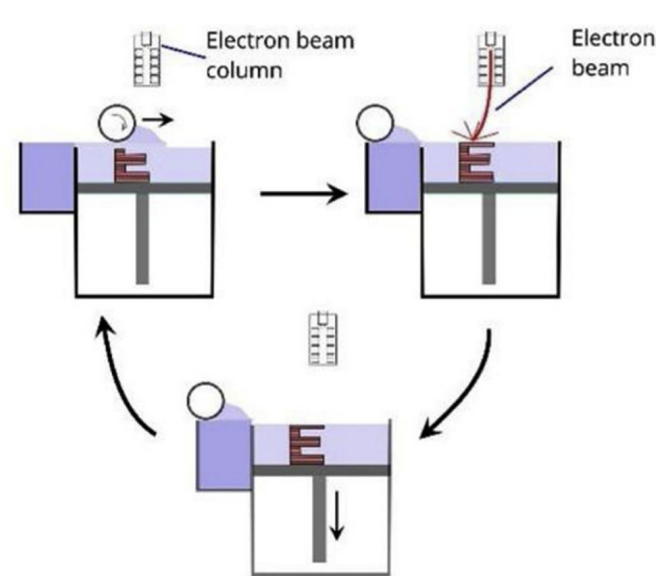

FIGURE 1 | Schematic diagrams of PBF including (A) SLS and SLM, and (B) EBM (Ataee et al., 2017). 
tungsten wire, and the direction and diameter of the electron beam are controlled by a magnetic lens (or coil) (Yuan et al., 2019). During sintering, the metal power melts entirely, and then the electron beam sweeps the powder along the preset path and processing parameters. The powders can be melted and solidified into a metal entity, finally forming a thin layer with a thickness of 0.05-0.2 $\mathrm{mm}$. Then the powders are spread and sintered again and this operation was repeated until the formation of parts entirely. To prevent the oxidation of the metal powder, the entire process needs to be carried out in a vacuum (Gokuldoss et al., 2017). EBM's advantages are lies in the higher energy density of the electron beam, faster rate of powder melting and forming (Liu et al., 2016). Due to the high energy density, EBM technology can prepare refractory metals with high melting points. During processing, EBM usually heats the powder bed, which can reduce the temperature differences between the powder bed and the metal. Thus the residual stress of parts is small (Gokuldoss et al., 2017). Like the SLM technology, the parts prepared by EBM have high surface roughness (Gong et al., 2014), and the dimensional error and surface integrity are worse than those of the cast one.

\section{THE METAL MATERIAL USED IN POROUS SCAFFOLDS}

\section{Non-biodegradable Metals}

The non-biodegradable metal materials currently used in porous scaffolds mainly include pure Ti (Wauthle et al., 2015a), Ti alloy (Kapat et al., 2017; Onal et al., 2018; Cutolo et al., 2020), Ta (Wauthle et al., 2015b), 316L stainless steel (Yan et al., 2014), NiTi alloy (Habijan et al., 2013), and Co-Cr alloy (Demir and Previtali, 2017), etc. Table 2 lists the mechanical properties of different non-biodegradable porous scaffolds (Peng et al., 2019). Ti alloys are widely used in orthopedic implants due to the better biocompatibility, corrosion resistance, and excellent mechanical properties (Zhu et al., 2016). Ti-6Al-4V has more matching elastic modulus with human bone and relatively low price (Yang et al., 2018; Lv et al., 2019), which is the most studied biomedical Ti alloy (Cheng et al., 2014; Zhu et al., 2018). However, cytotoxicity experiments of $\mathrm{Ti}-6 \mathrm{Al}-4 \mathrm{~V}$ scaffolds also indicate that the release of $\mathrm{Al}$ and $\mathrm{V}$ ions occurs in the human body, which affects cell proliferation and causes cytotoxicity (Surmeneva et al., 2019). Pure Ti, as a good biometal material, avoids the release of harmful ions (Liu J. et al., 2020). Wauthle et al. (2015b) and Liu S. et al. (2020) prepared pure Ti scaffolds with a dodecahedral unit structure and found that the scaffolds have higher fatigue cycle strength and ductility than that of Ti-6Al-4V. The $\mathrm{Nb}$ and $\mathrm{Zr}$ elements also have good biocompatibility (Sing et al., 2016) and have been used as alloying elements to improve the biological and mechanical properties of Ti alloys (Lin et al., 2013). Liang et al. (2020) prepared $\mathrm{Ti}-25 \mathrm{Nb}$ porous scaffolds with a hydrophilic surface structure. They found that $\mathrm{Ti}-25 \mathrm{Nb}$ scaffold can promote the expression of phagocyte M2 type and enhance the activity of anti-inflammatory phagocytes. Luo et al. (2020) found that the Ti-30Nb-5Ta-8Zr scaffold exhibits similar fatigue strength, compression, and tensile properties with cortical bone, and they also established the functional relationship between the porosity, yield strength, and elastic modulus of the alloy. Wauthle et al. (2015b) and Wang H. et al. (2019) prepared three type porous metal scaffolds, including $\mathrm{Ta}$, pure $\mathrm{Ti}$, and $\mathrm{Ti}-6 \mathrm{Al}-4 \mathrm{~V}$. They found that Ta porous scaffolds have the same cell proliferation, survival and osteogenic properties as Ti scaffolds. Moreover, the Ta scaffolds have better toughness and fatigue limit than Ti-6Al$4 \mathrm{~V}$ scaffolds (Guo et al., 2013). However, Ta scaffold has a higher price, which limits its wide application.

TABLE 2 | Mechanical properties of different porous metal scaffolds.

\begin{tabular}{|c|c|c|c|}
\hline \multicolumn{4}{|c|}{ Mechanical properties of porous metal scaffolds } \\
\hline Materials(structure) & Elastic modulus (GPa) & Yield strength (MPa) & References \\
\hline Ti-6Al-4V (Gyroid and Diamond) & 3.8 & 152.6145 .7 & Liu et al., 2018 \\
\hline Ti-6Al-4V (Octahedral) & $2.1-4.7$ & $71-190$ & Yan et al., 2019 \\
\hline Pure Ti (Diamond) & $0.557-0.661$ & 50 & Taniguchi et al., 2016 \\
\hline Pure Ti (FGPS) & $0.28-0.59$ & $3.79-17.75$ & Han et al., 2018 \\
\hline Pure Ta (Diamond) & 3.1 & 393.62 & Wang H. et al., 2019 \\
\hline Pure Ta (Dodecahedron) & 1.22 & 12.7 & Wauthle et al., 2015b \\
\hline Ti-30Nb-5Ta-8Zr (Rhombic dodecahedron, Body diagonals) & $0.7-4.4$ & $12.5-67$ & Luo et al., 2020 \\
\hline Ti35Zr28Nb (Face centered cubic) & 1.1 & 27 & Li et al., 2019a \\
\hline Ti-35Nb-2Ta-3Zr & 3.13 .53 .9 & 136137149 & Hafeez et al., 2020 \\
\hline CoCr F75 (Diamond) & 3.432 .322 .22 & 116.3475 .9778 .57 & Hooreweder et al., 2017 \\
\hline NiTi (Octahedron, Cellular gyroid, Sheet gyroid) & & 212944 & Speirs et al., 2017 \\
\hline $\mathrm{NiTi}$ & $3.7-13.5$ & & Bartolomeu et al., 2020; Liu S. et al., 2020 \\
\hline 316L (Gyroid) & 2.042 .482 .71 & 5572.189 .4 & Ma et al., 2019 \\
\hline 316L (Gyroid) & $14.41-15.53$ & $251-302$ & Yan et al., 2014 \\
\hline Fe (Diamond) & 2.810 .891 .771 .75 & 53.110 .732 .930 .5 & Li et al., 2019b \\
\hline Fe-35Mn (Schwarz Primitive) & 33.5 & 304 & Carluccio et al., 2020 \\
\hline Zn (Diamond) & 0.786 & 10.8 & Li et al., 2020c \\
\hline Mg WE43 (Diamond) & $0.7-0.8$ & 23 & Li et al., 2018 \\
\hline
\end{tabular}


Ma et al. (2019) prepared 316L stainless steel porous scaffolds and studied the influence of the pore size and porosity on their elastic modulus, yield strength, and permeability. They also established the functional relationship of the above parameters and predicted the permeability of the scaffold. Čapek et al. (2016) also obtained 316L stainless steel scaffolds with good mechanical properties and found that the mechanical properties are close to that of trabecular bone. However, compared with Ti alloy and Ta, stainless steel has a higher elastic modulus, which easily leads to stress shielding (Yamamoto et al., 2004). Thus how to adjust the pore size and porosity of scaffolds and balance their relationship between strength and elastic modulus is the crucial point for $316 \mathrm{~L}$ stainless steel porous scaffolds.

NiTi alloy has the characteristics of superelasticity and shape memory, which have a good application prospect in biomedical field (Wang L. et al., 2016; Liu et al., 2019). Nevertheless, the $\mathrm{Ni}$ ions in the alloy have cytotoxicity, which is a concerning matter to people. Habijan et al. (2013) prepared NiTi scaffolds with different porosity and surface morphology, and cultivated stem human mesenchymal stem cells (hMSC) on NiTi scaffolds. They found that the amount of $\mathrm{Ni}$ released in the porous scaffold is higher than that of the dense sample, but all were below the cytotoxic concentration. They also found that changing the spot diameter can improve the scaffold surface morphology, and reducing the spot diameter can reduce $\mathrm{Ni}$ ions' release. They believed that NiTi scaffolds are suitable carriers for hMSC, but the process parameters and postprocessing still need to be optimized before in vivo studies (Liu et al., 2021).

The Co-Cr alloy has good biocompatibility (Baldwin and Hunt, 2006), corrosion resistance, and wear resistance, and is widely used in orthopedic surgery, especially in hip replacement or knee replacement. However, the osseointegration and biomechanical properties of $\mathrm{Co}-\mathrm{Cr}$ alloy are inferior to $\mathrm{Ti}-6 \mathrm{Al}-$ $4 \mathrm{~V}$. Shah et al. (2016) prepared $\mathrm{Co}-\mathrm{Cr}$ and $\mathrm{Ti}-6 \mathrm{Al}-4 \mathrm{~V}$ porous scaffolds by EBM. In vivo implantation experiments found that the bone-implant bonding rate of the Co-Cr scaffold is lower than that of the Ti- $6 \mathrm{Al}-4 \mathrm{~V}$, but they have similar bone cell density and distribution in a newly formed bone. Caravaggi et al. (2019) prepared Co-Cr scaffolds with different porous structures by SLM, and found that the elastic modulus of porous structure is about $32 \mathrm{GPa}$, which is close to the elastic modulus of human bone. Cell culture experiments showed that the number of cells on the porous structure continued to increase over the course of 1 week, indicating that the $\mathrm{Co}-\mathrm{Cr}$ alloy had good biocompatibility.

\section{Biodegradable Metals}

The biodegradable metal can effectively avoid chronic local inflammation (Moravej and Mantovani, 2011), continuous physical stimulation (Song and Song, 2007), and implant-related infections, which has broad prospects in the biomedical field. At present, $\mathrm{Fe}, \mathrm{Mg}$, and $\mathrm{Zn}$ alloys are widely studied as materials for degradable scaffolds (Li et al., 2020b). How to match the rate of metal degradation to that of bone tissue ingrowth is the main challenge. Table 2 lists the mechanical properties of $\mathrm{Fe}, \mathrm{Mg}$, and $\mathrm{Zn}$ porous scaffolds.
$\mathrm{Fe}$ is an element needed by the human body, and also has good biocompatibility. The main problem for $\mathrm{Fe}$ is the slower degradation rate in the human body, which can inhibit the ingrowth rate of bone tissue. Li et al. (2019b) prepared gradient porous $\mathrm{Fe}$ scaffolds and the pore size of scaffolds are $600 \mu \mathrm{m}$ (S0.4), 600-800 $\mu \mathrm{m}$ (Dense-out), 800$600 \mu \mathrm{m}$ (Dense-in), and 800-600 $\mu \mathrm{m}$ (S0.2). They found that the scaffold of S0.2 and Dense-out had exactly the same structure in the center (Figure 2B), but the weight loss of the Dense-out scaffold in the center was higher than that of the S0.2 scaffold, as shown in Figure 2C. They believe that the Dense-out scaffold has higher flow velocities in the center than on the periphery, as shown in Figure 2D. Adding alloy elements into the $\mathrm{Fe}$ can also affect its degradation rate. Carluccio et al. (2019) prepared Fe and Fe-Mn porous scaffolds. They found that the corrosion rate of $\mathrm{Fe}-\mathrm{Mn}$ scaffold is much higher than that of pure Fe. They believed that a galvanic cell is formed between the different metal scaffolds, which accelerates $\mathrm{Fe}-\mathrm{Mn}$ alloy's degradation. The FeMn alloy scaffold has good biocompatibility and vitality to mammalian cells.

$\mathrm{Mg}$ alloy porous scaffolds have a higher degradation rate, leading to its complete degradation before bone tissue fully grows into the scaffolds. To decrease the degradation rate, surface modification (plasma electrolytic oxidation), and heat treatment of the scaffold were performed by Kopp et al. (2019). They found that Mg hydroxide and oxide are formed on the scaffold surface, which slows down the degradation rate in the simulated body fluid. $\mathrm{Mg}$ is more active, and there are problems such as difficulty in preparation, powder splashing, cracks, and so on (Wang et al., 2020d). The degradation rate of Mg scaffolds also can produce hydrogen that affects cell proliferation. They believed that if the problems mentioned above can be dealt with, $\mathrm{Mg}$ alloys will have a more significant impact in the biomedical field.

$\mathrm{Zn}$ alloys have gradually attracted extensive attention from researchers because their degradation rate is closest to bone tissue (Su et al., 2019; Fu et al., 2020), which is very beneficial to the healing of bone tissue. Li et al. (2020c) prepared Zn scaffolds with a diamond structure and found that the mechanical properties are similar to cancellous bone. The volume loss is 7.8 and $3.6 \%$, respectively, after 28 days of dynamic and static immersion in vitro, and the degradation rate is between $\mathrm{Mg}$ and $\mathrm{Fe}$, as shown in Figure 2A. The mechanical properties of the $\mathrm{Zn}$ scaffolds after soaking can be improved after a small amount of degradation. Cockerill et al. (2020) prepared Zn scaffolds with different pore sizes through combination methods of $\mathrm{AM}$ and casting and found that the $\mathrm{Zn}$ scaffolds have good biocompatibility and antibacterial properties.

\section{High Entropy Alloys}

Compared with traditional metals and alloys, high-entropy alloys are gradually becoming a focus of attention due to their better comprehensive properties. These alloys are no longer based on a particular component, but are made of a variety of metal to provide better properties such as strength, corrosion resistance, and biocompatibility (Ma et al., 2020). 


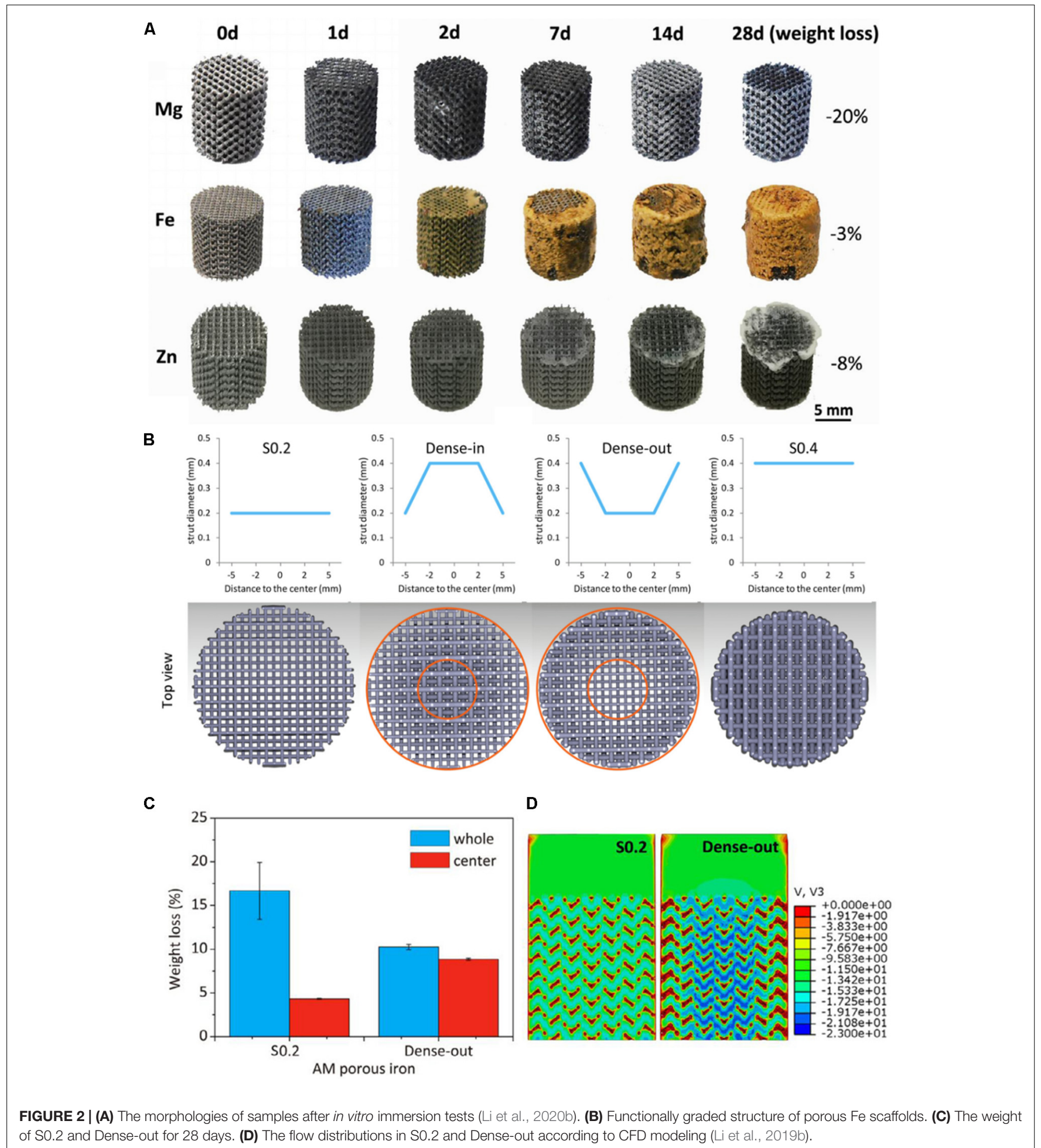

Motallebzadeh et al. (2019) prepared TiZrTaHfNb and $\mathrm{Ti}_{1.5} \mathrm{ZrTa}_{0.5} \mathrm{Hf}_{0.5} \mathrm{~N}_{b 0.5}$ high entropy alloys and compared their properties with $316 \mathrm{~L}, \mathrm{CoCrMo}$, and Ti6Al4V alloys. They found that the high entropy alloy show higher wear resistance and corrosion resistance. They attributed the higher mechanical properties to the "cocktail effect" of the high entropy alloy. Nagase et al. (2019) developed novel $\mathrm{TiZrHfCrO}{ }_{2} \mathrm{Mo}$ and $\mathrm{TiZrHfCo}_{0.07} \mathrm{Cr}_{0.07} \mathrm{Mo}$ high-entropy alloys for metallic biomaterials based on the combination of $\mathrm{Ti}-\mathrm{Nb}-\mathrm{Ta}-\mathrm{Zr}-$ Mo and Co-Cr-Mo alloy systems. The experimental results showed that newly developed high entropy has comparable biocompatibility with pure Ti. 


\section{THE STRUCTURE DESIGN OF POROUS METAL SCAFFOLDS}

The ideal scaffold should be a porous structure in space that provides space for cells to adhere, grow and proliferate, and have mechanical properties similar to the bone tissue (Cheng et al., 2014). Pore size and porosity are very important structural parameters, which have a direct impact on mechanical properties and biocompatibility of bone scaffolds. Proper pore size can provide growth space for cells, and proper porosity can ensure transportation of nutrients and metabolites in bone tissue (Cheng et al., 2014). Besides, the shape of the porous scaffold structure is also related to the biocompatibility and mechanical properties. The continuous and smooth porous structure can avoid stress concentration and facilitate the attachment of cells to the scaffold surface.

Porous scaffold prepared by the traditional foaming (Murray, 2003) and sintered microsphere methods (Mark et al., 2002) has a single structural unit, and the shape, size, and spatial distribution can not be precisely controlled. With the development of computer-aided design and AM technologies, problems as mentioned above have gradually been improved. AM technologies not only can accurately control the porous scaffold size and spatial structure distribution but also can obtain ideal mechanical properties and biocompatibility of porous scaffold by adjusting the pore size and porosity. In this section, the pore size and porosity of the scaffold are described, and the influence of pore size and porosity on the scaffold's performance are summarized. Then current design methods for porous metal scaffold including CAD structure, topology optimization, minimal surface structure, Voronoi mosaic method, CT imaging method, etc. are systematically reviewed.

\section{Pore Size and Porosity of the Porous Metal Scaffold}

The porous scaffold's pore size is generally defined by the inscribed circle method, as shown in Figure 3. The definition of porosity is the percentage of pore space in the solid structure given by the following formula:

Porosity $=\left(1-V_{P} / V_{S}\right) \times 100 \%$

Among them: $V_{P}$ is the volume of the porous structure and $V_{S}$ is the volume of the dense structure.

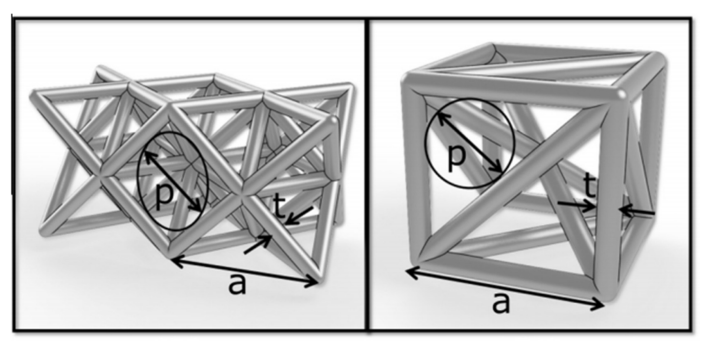

FIGURE 3 | Basic structural unit: p: aperture, t: pillar thickness (Arabnejad et al., 2016).

\section{The Influence of Pore Size and Porosity on Biocompatibility}

Many investigations reported that the optimal pore size and porosity of the porous scaffold are about 200-1200 $\mu \mathrm{m}$ (Ataee et al., 2018) and 60-95\% (Zhou et al., 2015), respectively. To explore a more specific range of porosity, $\mathrm{Ma}$ et al. (2020b) prepared convolute structured scaffolds with a porosity of $75-88 \%$ to study the effect of different porosity on cell proliferation. They found that a scaffold with a porosity of $88.8 \%$ has the largest number of cells, and they believed that increasing porosity could increase the specific surface area of the porous scaffold and improve its permeability.

Ouyang et al. (2019) explored the pore size's effect on the biocompatibility of porous scaffolds and designed Ti-6Al-4V scaffolds with pore sizes of 400, 650, 850, and $1100 \mu \mathrm{m}$, respectively. They found that increasing pore size can reduce the thickness and specific surface area of the pillar and increase the scaffolds's permeability. Cell proliferation and in vivo bone formation first increase and then decrease with the increase of pore size, and the best pore size is $650 \mu \mathrm{m}$. Ran et al. (2018) compared the bone ingrowth of Ti-6Al-4V scaffolds with a different pore sizes $(400,600$, and $800 \mu \mathrm{m})$. They found that the bone ingrowth properties of the scaffold with pores size of $800 \mu \mathrm{m}$ and $600 \mu \mathrm{m}$ is significantly better than that of $400 \mu \mathrm{m}$.

Wang S. et al. (2019) compared the biocompatibility of Ti$6 \mathrm{Al}-4 \mathrm{~V}$ scaffold with different structures, including OTC, TC, and OTC+TC (PFGS) structures. They found that the OTC structure has the fastest cell proliferation in 1-4 days, and the PFGS structure has the fastest cell proliferation in 4-7 days. In contrast, TC structure has slowest cell proliferation in 1-7 days. They believed that increasing the pore size can improve the permeability of the structure and high permeability can transport more oxygen and nutrients, which is conducive to cell growth in the early stage of cell culture (Wang et al., 2020c). PFGS has a smaller inner hole that is conducive to cell adhesion and differentiation, so the PFGS structure shows a higher cell proliferation rate in the later stage of cell culture.

\section{The Influence of Pore Size and Porosity on Mechanical Properties}

The dense metal materials have a much higher elastic modulus than human bone. For example, the elastic modulus of pure $\mathrm{Ti}$ and $\mathrm{Ti}-6 \mathrm{Al}-4 \mathrm{~V}$ are 112 and $132 \mathrm{Gpa}$, respectively (Sing et al., 2016). While the elastic modulus of trabecular or cancellous bone is between 0.02 and $2 \mathrm{Gpa}$ (Wang X. et al., 2016), cortical bone is higher, ranging from 7.7 to $21.8 \mathrm{Gpa}$ (Zhang et al., 2018). At present, the implant's elastic modulus is mainly controlled by adjusting the pore size and porosity. Yan et al. (2015) prepared Ti-6Al-4V scaffolds with $\mathrm{G}$ and $\mathrm{D}$ structures with a porosity of $80-95 \%$, a pore size of $480-1600 \mu \mathrm{m}$, and found that the elastic modulus is about $0.12-1.25 \mathrm{GPa}$. The pore size and porosity of scaffold also have immediate impact on strength (Ran et al., 2018). Zhao et al. (2019) prepared octahedral structured Ti-6Al$4 \mathrm{~V}$ porous scaffolds with pore sizes of 500 and $1000 \mu \mathrm{m}$ and found that increasing pore size can decrease the tensile strength and fatigue strength. Therefore, increasing the pore size and can 
reduces the elastic modulus, but it will also cause a decrease in the tensile strength and fatigue strength of the scaffold.

\section{Structure Design Methods of Porous Metal Scaffold \\ CAD Method}

The main principle of the CAD method is to design different types of hole-making units and then create a porous scaffold through the Boolean operation (Zhao et al., 2018). As the basic unit of a porous scaffold, the shape, porosity, pore size, and surface area have a direct impact on the overall performance. Thus in the early stage, researchers mainly focused on the design of the hole-making unit. Based on bionic characteristics of different parts of human bones, Sun et al. (2005) designed structural units with disk and rod shapes using computer-aided tissue technology (CATE). They obtained a combination of different units by adding the same circular boundary on different units. Finally, a unit library that can combine multiple structural units was established. Chua et al. (2003) used the CAD method to develop a standard unit library containing 11 kinds of hole elements and developed

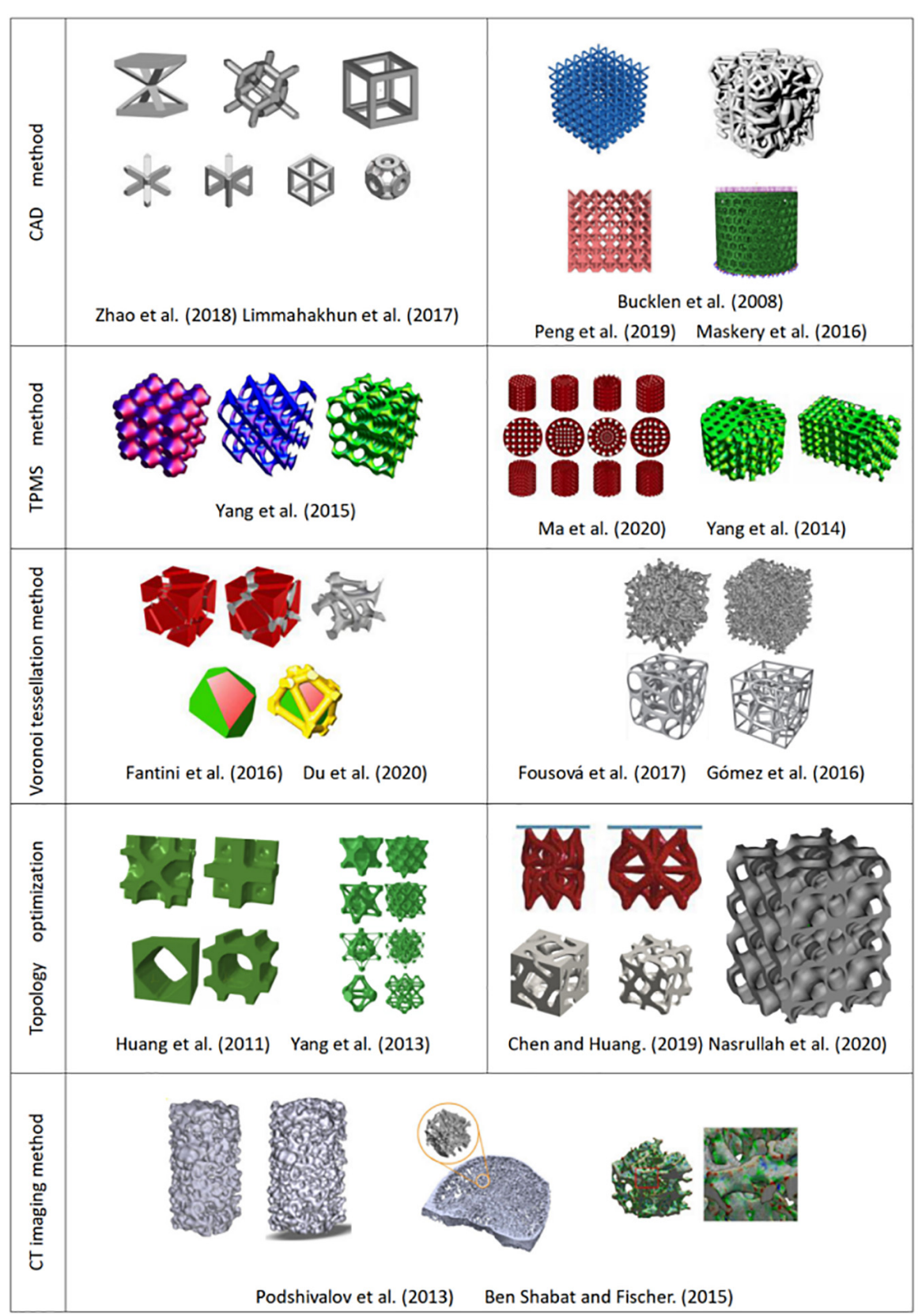

FIGURE 4 | Structures designed by different design methods. 
an automatic assembly unit to match the anatomical shape of bone tissue. Polyhedra and lattice structure play an important role in CAD design due to their simple structure and good mechanical properties. Maskery et al., 2016 designed a gradient BCC (body centered cubic) lattice model (see Figure 4) to compare their mechanical properties and energy absorption with a uniform one. They found that the gradient structure is able to absorb around $114 \%$ higher energy than uniform structure. Li et al. (2019a) established the FCC (face-centered cubic structure) and BCC lattice models, and they considered that this simple and reliable models can obtain the desired mechanical properties and biocompatibility. Limmahakhun et al. (2017) established four structures (octahedron, column octahedron, cube and truncated octahedron), as shown in Figure 4. The mechanical tests and in vitro cellular experiments showed that the column octahedron structure can balance mechanical and biological properties, and are more suitable as the basic unit of bone scaffold. Although created units using CAD method are simple and have a low mechanical property (Wettergreen et al., 2005; Chantarapanich et al., 2012), the method still provides ideas for the following research.

\section{Triple Periodic Minimal Surface (TPMS) Structure}

A minimal surface is an implicit equivalent surface with zero mean curvature. If the minimal surface is periodic in three independent directions, it is usually called triple periodic minimal surface (TPMS). TPMS can be expressed by a trigonometric function, as shown in Table 3. Changing the TPMS's threshold value can accurately control the internal pore structure, optimize the gradient pore structure, and maximize the specific surface area of the scaffold.

Yoo (2011b) proposed a three-dimensional bone scaffold design method that integrated distance field algorithms and TPMS curved surfaces. This method can automatically obtain a bone scaffold model with complex microstructures and high quality free-form external surfaces. Yoo (2011a) proposed another TPMS design method that two different TPMS structures can be combined by using a linear interpolation algorithm. Yang et al. (2014) reported that smooth transition between multiple different TPMS substructures could be combined by sigmoid and Gaussian radial basis functions (Yang and Zhou, 2014; Yang et al., 2015). Ma et al. (2020a) proposed a new method for designing heterogeneous porous scaffolds, that is, TPMS units were combined with grid units using shape functions, and they obtained a conformal refined discrete scaffold of a full hexahedral grid. After finite element analysis, they found that the elastic modulus, strength, and energy absorption of the heterogeneous scaffolds are significantly improved than uniform structure.

Nature bone has a porous gradient structure; thus, the gradient TPMS structure is a hot spot in scaffolds design (Almeida and Bártolo, 2014; Zhou et al., 2020). Wang et al. (2020c) designed a symmetrical gradient Ti-6Al-4V scaffolds with a $\mathrm{P}$ structure. They found that the gradient structure has better mechanical performance than that of the uniform structure.

TABLE 3 | Common minimal surface structures.

TPMS unit Mathematical expressions

$P\left(\right.$ SchwarzP) structure $\quad \varphi(x, y, z)=\cos \left(\omega_{x} x\right)+\cos \left(\omega_{y} y\right)+\cos \left(\omega_{z} z\right)=C$

D (Diamond) structure $\quad \varphi(x, y, z)=\cos \left(\omega_{x} x\right) \cos \left(\omega_{y} y \cos \left(\omega_{z} z\right)-\sin \left(w_{x} x\right) \sin \left(w_{y} y\right) \sin \left(w_{x} z\right)=C\right.$
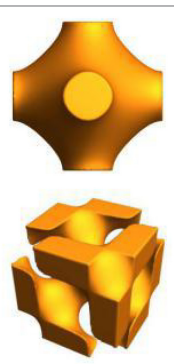

G (Gyroid) structure $\quad \varphi(x, y, z)=\sin \left(\omega_{x} x\right) \cos \left(\omega_{y} y\right)+\sin \left(\omega_{y} y\right) \cos \left(\omega_{z} z\right)+\sin \left(\omega_{z} z\right) \cos \left(\omega_{x} x\right)=C$
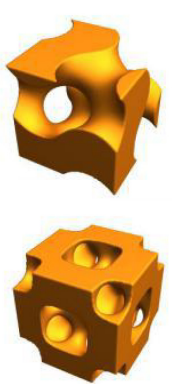

F-RD structure

$\varphi(x, y, z)=4 \cos \left(\omega_{x} x\right) \cos \left(\omega_{y} y\right) \cos \left(\omega_{z} z\right)-\left[\cos \left(2 \omega_{x} x\right) \cos \left(2 \omega_{y} y\right)+\cos \left(2 \omega_{z} z\right) 2\left(\omega_{x} x\right)+\cos \left(2 \omega_{y} y\right) \cos \left(2 \omega_{z} z\right)\right]=C$ 
Zhang X.Y. et al. (2020) proposed a new method that flexible control of structural parameters can be realized by changing the TPMS equation and found that those structure design parameters have obviously effects on the scaffold performance.

\section{Voronoi Tessellation Method}

Voronoi tessellation is a space division method based on seed points (Du et al., 2020). The seed points are connected through a specific algorithm to form a space polygon surrounding the seed points. Based on these polygonal edges, irregular porous scaffolds are generated (Xiao and Yin, 2016). Thus the internal structure of natural bone can be well simulated by irregular porous scaffolds based on the Voronoi tessellation principle.

Kou and Tan (2010) proposed a design method with controllable shape and distribution by using the twodimensional Voronoi diagram and they obtained irregular concave and convex polygons through the merging of Voronoi units. Then the boundaries of the concave and convex polygons were interconnected to form a bracket. The method makes a heterogeneous porous structure easier and maintain the irregularities in natural bone. Fantini et al. (2016) and Fantini and Curto (2017) used the three-dimensional Voronoi tessellation method to design porous structures, and obtained the three-dimensional Voronoi unit by processing the three-dimensional coordinates, and established the porous structure by Boolean operation on Voronoi unit, as shown in Figure 4. Lei et al. (2020) proposed a new Voronoi tessellation method to control the distribution of seed points and established a function relationship of the porosity and the number of seed points. Through this method, they obtained a Voronoi tessellation scaffold with a gradient distribution of seed points, which realizes the global control of the lattice porous structure.

The Voronoi tessellation method can generate an irregular pore model with controllable pore size and distribution, and the automation degree of generating the model is relatively higher. However, this method can not generate complicate porous structure due to the difficulty in the visualization of the porous scaffolds (Wang et al., 2020b).

\section{Topology Optimization}

Topology optimization technology is a mathematical method based on finite elements (Marinela et al., 2019), which can rearrange materials or structures to obtain the required mechanical properties (Zhao et al., 2014). It is a powerful method for the design of complex structures with multi-scale features (Chen and Huang, 2019).

Yang et al. (2013) proposed a topology optimization method of periodic hole unit structure and designed a porous scaffold with a required Young's modulus, as shown in Figure 4. Radman et al. (2012) specified the volume or shear modulus of units, and optimized the primary unit through the antihomogeneous two-way advanced optimization technology, and established functionally gradient porous structure by the proper connection between adjacent basic units. Xiao et al. (2012) rearranged the structure of the model under the constraint of volume fraction to achieve the ideal stiffness through the topology optimization method and obtain optimal three-dimensional structure of porous scaffolds (Xiao et al., 2013). Nasrullah et al. (2020) established 11 kinds of porous structures by topology optimization of lattice structures, and reported a conical lattice structure that can provide energy absorption of up to $127 \mathrm{~kJ} / \mathrm{kg}$. Zhang L. et al. (2020) combined the topology optimization with numerical homogenization method to design high stiffness lattice structure, and successfully obtained a new lattice structure with high load-bearing and energy absorption capacity, and the relative elastic modulus can reach 0.037 .

Topology optimization methods can combine with a variety of design methods to achieve required mechanical properties and biocompatibility (Wang X. et al., 2016; Park et al., 2018). Nevertheless, the design methods have many variables and high calculations (Zhang X.Y. et al., 2019). How to balance the relationship between structural design and calculation efficiency remains to be resolved (Dias et al., 2014).

\section{CT Imaging Method}

The main principle of CT imaging method is to analysis and processing of CT or MRI images (Feinberg et al., 1999) and to extract key features by various reconstruction algorithms to perform three-dimensional reconstruction. The modeling flow chart is shown in Figure 5.

Hollister (2005) performed gray-scale processing of medical images and obtained the distribution of solid voxel and void information using a binarization segmentation algorithm. Then

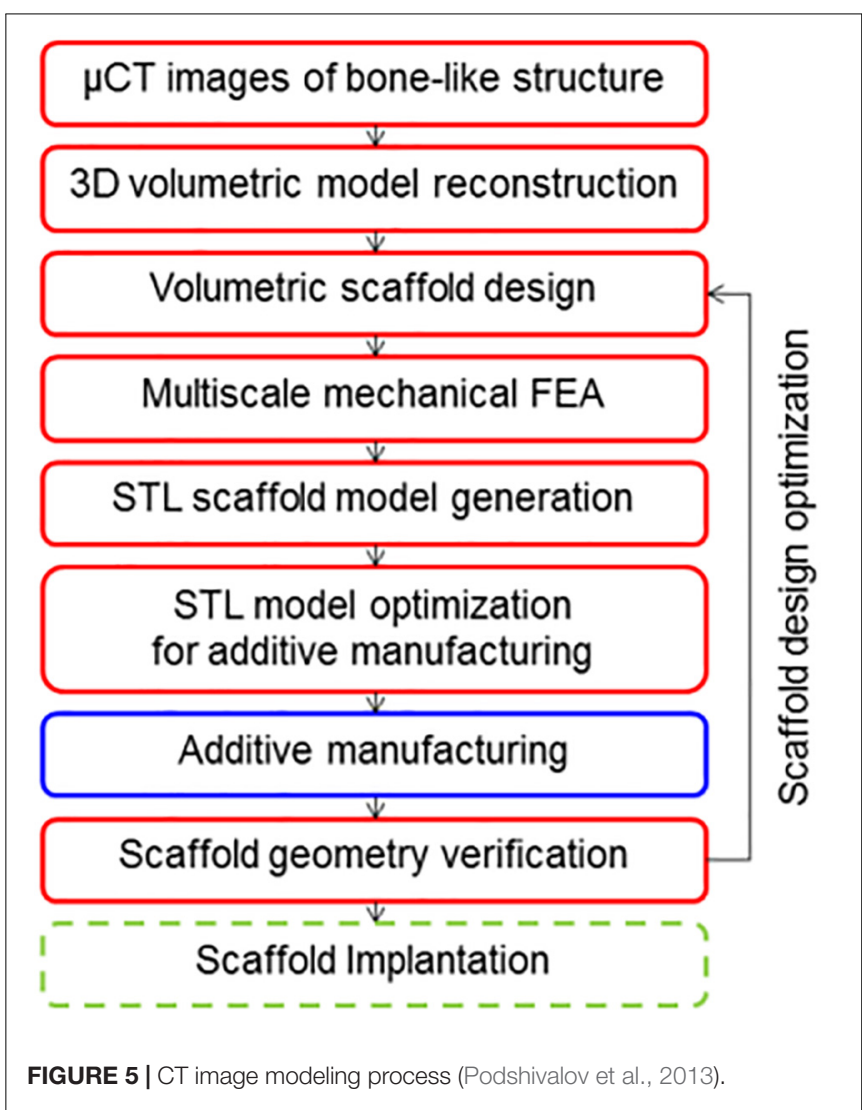


they established the porous structure by mapping the defined porous structure unit to the solid voxel. Podshivalov et al. (2013) segmented the CT image and removed the redundant shadow part, then repaired hole on the model, and finally obtained ideal bone scaffold model, as shown in Figure 4. Ben and Fischer (2015) made important progress in CT image adaptive model reconstruction. They introduced the quadtree and octree algorithms into the process of adaptive model reconstruction, which greatly simplifies the modeling process. Zheng et al. (2020) scanned skull samples, extracted the shape of the skull and reconstructed inside structure of the trabecular. Cell cultures experiment showed that the model restores the internal structure of the skull, and has good biocompatibility. The CT imaging method can produce porous structure closest to the threedimensional structure inside the bone tissue (Cai, 2008; Cai and Xi, 2009; Cai et al., 2012). However, the method has a high dependence on the image resolution ( $\mathrm{Li}$ et al., 2006), and the simplification processing of CT or MRI data is relatively cumbersome, which leads to certain restrictions on its clinical application (Jones et al., 2007).

\section{Comparison of Porous Scaffold Design Methods}

At present, CAD design and topology optimization methods are the widely used methods in the design of porous scaffolds because these methods are simple and reliable, and simultaneously meeting the basic requirements of reducing the modulus of the scaffolds. The structures designed by TPMS and Voronoi methods are more similar to the internal structure of human bone, and they have better permeability and mechanical properties than the structure designed by CAD method. The
CT imaging method can reflect the real structure of bone. If the reconstruction process of the model can be simplified, it is believed that the CT imaging method can be further developed. The comparisons of these modeling methods are summarized, as shown in Table 4.

The above is the comparison and summary of structural unit design methods. In addition, we also pay attention to the overall design of the scaffold, and the hierarchical structure is the hot spot in the overall design of the scaffold (He et al., 2021). The real shape of bone in human body is the porous structure with gradient distribution. According to the size and porosity of the pores, bone can be divided into dense and cancellous bone from the outside to the inside (Du et al., 2019). Only vascular and nerve channels remain in dense bone, with a porosity of about $5-30 \%$. Cancellous bone has a porosity of $30-90 \%$, and can deform under stress and absorb energy shocks from outside (Liu et al., 2018). The hierarchical structure of natural bone in human body can not only meet the needs of material transportation, but also meet the requirements of mechanical properties. Singh et al. (2010) and Huang et al. (2014) demonstrated that the hierarchical structure of the scaffold can produce anisotropic mechanical properties, which are more similar to the mechanical properties of human bones than the homogeneous structure. If the unit design is combined with the overall hierarchical design, scaffolds with better comprehensive performance can be obtained.

\section{SUMMARY AND OUTLOOK}

Additive manufacturing technology provides unprecedented opportunities for the production of customized biomedical

TABLE 4 | Comparison of porous scaffold design methods.

\begin{tabular}{|c|c|c|c|c|c|}
\hline Methods & Structures & Design principle & Advantages & Disadvantages & References \\
\hline CAD method & & $\begin{array}{l}\text { Boolean operations } \\
\text { between unit structures }\end{array}$ & $\begin{array}{l}\text { - Low cost } \\
\text { - High efficiency } \\
\text { - Good permeability }\end{array}$ & $\begin{array}{l}\text { - Poor controllability of } \\
\text { parameters } \\
\text { - Poor mechanical } \\
\text { properties }\end{array}$ & $\begin{array}{l}\text { Zhao et al., 2018; } \\
\text { Maconachie et al., 2019; } \\
\text { Ren et al., } 2019\end{array}$ \\
\hline TPMS method & & $\begin{array}{l}\text { Modeling of } \\
\text { trigonometric function } \\
\text { expression of minimal } \\
\text { surface }\end{array}$ & $\begin{array}{l}\text { - Smooth transition } \\
\text { - Large specific surface } \\
\text { area } \\
\text { - Good controllability of } \\
\text { parameters }\end{array}$ & - Small function coverage & $\begin{array}{l}\text { Yoo, 2011b; Abueidda } \\
\text { et al., 2019; Yu et al., } 2019\end{array}$ \\
\hline Topology optimization method & & $\begin{array}{l}\text { According to } \\
\text { requirements, } \\
\text { optimized by finite } \\
\text { element method }\end{array}$ & $\begin{array}{l}\text { - Combine with multiple } \\
\text { design methods } \\
\text { - Good mechanical } \\
\text { properties } \\
\text { - Good permeability }\end{array}$ & $\begin{array}{l}\text { - Variable and complex } \\
\text { parameters }\end{array}$ & $\begin{array}{l}\text { Challis et al., 2010; Yang } \\
\text { et al., } 2013\end{array}$ \\
\hline Voronoi tessellation method & & $\begin{array}{l}\text { Based on the seed } \\
\text { point, surround the } \\
\text { seed point to form a } \\
\text { spatial polygon, and } \\
\text { build a support based } \\
\text { on the edge of the } \\
\text { polygon }\end{array}$ & $\begin{array}{l}\text { - Simulate the irregular } \\
\text { porosity of natural bone } \\
\text { - Good controllability of } \\
\text { parameters }\end{array}$ & $\begin{array}{l}\text { - Poor mechanical } \\
\text { performance } \\
\text { - Complex relationship } \\
\text { between parameters and } \\
\text { performance }\end{array}$ & $\begin{array}{l}\text { Gómez et al., 2016; Fantini } \\
\text { et al., 2016; Fantini and } \\
\text { Curto, } 2017\end{array}$ \\
\hline CT imaging method & & $\begin{array}{l}\text { Extract the key shape } \\
\text { features of the CT } \\
\text { images and perform 3D } \\
\text { reconstruction }\end{array}$ & $\begin{array}{l}\text { - Internal structure closest } \\
\text { to natural bone } \\
\text { - Good permeability }\end{array}$ & $\begin{array}{l}\text { - Complex data processing } \\
\text { - High equipment } \\
\text { requirements }\end{array}$ & Gómez et al., 2016 \\
\hline
\end{tabular}


implants. With the development of materials science and computer-assisted technologies, metal porous scaffolds produced by AM, additive manufacturing have been applied in clinical practice. In the future, the preparation of porous metal scaffolds by $\mathrm{AM}$, additive manufacturing still has great potential in the following fields.

(1) The metal scaffolds with degradable materials can effectively reduce the subsequent maintenance problems of the implant. However, the most widely used materials for metal porous scaffolds are still non-degradable metals such as pure $\mathrm{Ti}, \mathrm{Ti}$ alloys, $316 \mathrm{~L}$ and so on. So it is particularly important to design and prepare new biodegradable materials that matching degradation rate with bone tissue.

(2) Real bone in the human body has gradient microstructures; thus the development of porous scaffolds with gradient structure is a future development trend. At present, it is challenging to obtain a gradient scaffold with better performance with a single design method. Therefore, combination methods of topology optimization, CAD and minimal surface and so on. Can be tried to design the gradient structure in the future.

(3) Surface modification can effectively improve the osteogenesis, bacteriostasis, and biocompatibility of porous scaffolds. At present, preparation of inorganic and organic surfaces, or changing the surface morphologies of bone implants are the main surface modification methods. In the future, new surface modification materials and methods used for porous scaffolds should be developed in order to improve its biocompatibility or realize the treatment of certain diseases.

(4) At present, most of the researches on the biocompatibility of the scaffold only stays in cell experiments, which lacks accurate evaluation of the scaffold performances. Thus effective in vivo osteogenic experiment should be introduced and biological standards should be established

\section{REFERENCES}

Abueidda, D. W., Elhebeary, M., Shiang, C.-S., Pang, S., Abu Al-Rub, R. K., and Jasiuk, I. M. (2019). Mechanical properties of 3D printed polymeric gyroid cellular structures: experimental and finite element study. Mater. Des. 165:107597. doi: 10.1016/j.matdes.2019.107597

Ahmadi, S. M., Kumar, R., Borisov, E. V., Petrov, R., Leeflang, S., Li, Y., et al. (2019). From microstructural design to surface engineering: a tailored approach for improving fatigue life of additively manufactured meta-biomaterials. Acta Biomater. 83, 153-166. doi: 10.1016/j.actbio.2018.10.043

Almeida, H. A., and Bártolo, P. J. (2014). Design of tissue engineering scaffolds based on hyperbolic surfaces: structural numerical evaluation. Med. Eng. Phys. 36, 1033-1040. doi: 10.1016/j.medengphy.2014.05.006

Arabnejad, S., Burnett Johnston, R., Pura, J. A., Singh, B., Tanzer, M., and Pasini, D. (2016). High-strength porous biomaterials for bone replacement: a strategy to assess the interplay between cell morphology, mechanical properties, bone ingrowth and manufacturing constraints. Acta Biomater. 30, 345-356. doi: 10. 1016/j.actbio.2015.10.048

Ataee, A., Li, Y., Fraser, D., Song, G., and Wen, C. (2018). Anisotropic Ti-6Al$4 \mathrm{~V}$ gyroid scaffolds manufactured by electron beam melting (EBM) for bone implant applications. Mater. Des. 137, 345-354. doi: 10.1016/j.matdes.2017. 10.040 to more scientifically evaluate the osteogenic ability of porous scaffolds.

(5) $4 \mathrm{D}$ printing is a concept that has emerged in recent years, which generally refers to programmatical change in shape and function of $3 \mathrm{D}$ printed scaffolds over time. The change can adjust the mechanical properties or structure characteristics of the porous scaffolds and expand its functions and applications, providing a broader prospect for the development of porous scaffolds.

\section{AUTHOR CONTRIBUTIONS}

YT carried out the conception of the idea of the manuscript. ZQ and JL provided the data and advice. BW and GL collected and collated the data. YL wrote the original draft. EL reviewed and revised the original draft. $\mathrm{KX}$ and $\mathrm{CL}$ provided guidance for the revision of the manuscrip. LW provided the financial support for the project to this publication. All the authors contributed to the article and approved the submitted version.

\section{FUNDING}

The authors would like to acknowledge the financial supports provided by National Science Foundation under Grant No. 51801115, the China Postdoctoral Science Foundation (Grant No. 2020M671112), High-level Innovation team and Outstanding Scholars Program of Colleges and Universities in Guangxi: innovative team of basic and Clinical Comprehensive Research on Bone and Joint degenerative Disease, Project of Science and Technology Innovation Base under the Central Guidance of local Science and Technology Development (Guike Jizi [2020] No. 198): Science and Technology Innovation Base for basic Research and Transformation of bone and joint degenerative diseases.

Ataee, A., Li, Y., Song, G., and Wen, C. (2017). Metal scaffolds processed by electron beam melting for biomedical applications. Metallic Foam Bone 3, 83-110. doi: 10.1016/b978-0-08-101289-5.00003-2

Bae, E.-J., Kim, J.-H., Kim, W.-C., and Kim, H.-Y. (2014). Bond and fracture strength of metal-ceramic restorations formed by selective laser sintering. J. Adv. Prosthodont. 6, 266-271. doi: 10.4047/jap.2014.6. 4.266

Baldwin, L., and Hunt, J. A. (2006). Host inflammatory response to NiCr. CoCr, and Ti in a soft tissue implantation model. J. Biomed. Mater. Res. A 79, 574-581. doi: 10.1002/jbm.a.30856

Bartolomeu, F., Costa, M. M., Alves, N., Miranda, G., and Silva, F. S. (2020). Engineering the elastic modulus of NiTi cellular structures fabricated by selective laser melting. J. Mech. Behav. Biomed. Mater. 110:103891. doi: 10.1016/ j.jmbbm.2020.103891

Ben, S. Y., and Fischer, A. (2015). Design of porous micro-structures using curvature analysis for additive-manufacturing. Procedia CIRP. 36, 279-284. doi: 10.1016/j.procir.2015.01.057

Bose, S., Ke, D., Sahasrabudhe, H., and Bandyopadhyay, A. (2018). Additive manufacturing of biomaterials. Prog. Mater. Sci. 93, 45-111. doi: 10.1016/j. pmatsci.2017.08.003

Bundy, K. J. (2008). Biomaterials and the chemical environment of the body. Joint Replacement Technology 44, 56-80. doi: 10.1533/9781845694807.1.56 
Cai, S. (2008). A control approach for pore size distribution in the bone scaffold based on the hexahedral mesh refinement. Comput. Aided Des. 40, 1040-1050. doi: 10.1016/j.cad.2008.09.004

Cai, S., and Xi, J. (2009). Morphology-controllable modeling approach for a porous scaffold structure in tissue engineering. Virtual Phys. Prototyp. 4, 149-163. doi: $10.1080 / 17452750903208467$

Cai, S., Xi, J., and Chua, C. K. (2012). A novel bone scaffold design approach based on shape function and all-hexahedral mesh refinemen. Comput. Aided Tissue Eng. 868, 45-55. doi: 10.1007/978-1-61779-764-4_3

Čapek, J., Machová, M., Fousová, M., Kubásek, J., Vojtěch, D., Fojt, J., et al. (2016). Highly porous, low elastic modulus 316L stainless steel scaffold prepared by selective laser melting. Mater. Sci. Eng. C 69, 631-639. doi: 10.1016/j.msec.2016. 07.027

Caravaggi, P., Liverani, E., Leardini, A., Fortunato, A., Belvedere, C., Baruffaldi, F., et al. (2019). CoCr porous scaffolds manufactured via selective laser melting in orthopedics: topographical, mechanical, and biological characterization. J. Biomed. Mater. Res. Part B 107, 2343-2353. doi: 10.1002/jbm.b.34328

Carluccio, D., Demir, A. G., Caprio, L., Previtali, B., Bermingham, M. J., and Dargusch, M. S. (2019). The influence of laser processing parameters on the densification and surface morphology of pure $\mathrm{Fe}$ and $\mathrm{Fe}-35 \mathrm{Mn}$ scaffolds produced by selective laser melting. J. Manuf. Processes 40, 113-121. doi: 10. 1016/j.jmapro.2019.03.018

Carluccio, D., Xu, C., Venezuela, J., Cao, Y., Kent, D., Bermingham, M., et al. (2020). Additively manufactured iron-manganese for biodegradable porous load-bearing bone scaffold applications. Acta Biomater. 103, 346-360. doi: 10. 1016/j.actbio.2019.12.018

Challis, V. J., Roberts, A. P., Grotowski, J. F., Zhang, L.-C., and Sercombe, T. B. (2010). Prototypes for bone implant scaffolds designed via topology optimization and manufactured by solid freeform fabrication. Adv. Eng. Mater. 12, 1106-1110. doi: 10.1002/adem.201000154

Chantarapanich, N., Puttawibul, P., Sucharitpwatskul, S., Jeamwatthanachai, P., Inglam, S., and Sitthiseripratip, K. (2012). Scaffold library for tissue engineering: a geometric evaluation. Comput. Math. Method. M. 2012, 1-14. doi: 10.1155/ 2012/407805

Chen, S. Y., Kuo, C. N., Su, Y. L., Huang, J. C., Wu, Y. C., Lin, Y. H., et al. (2018). Microstructure and fracture properties of open-cell porous Ti-6Al-4V with high porosity fabricated by electron beam melting. Mater. Charact. 138, 255-262. doi: 10.1016/j.matchar.2018.02.016

Chen, W., and Huang, X. (2019). Topological design of 3D chiral metamaterials based on couple-stress homogenization. J. Mech. Phys. Solids 131, 372-386. doi: 10.1016/j.jmps.2019.07.014

Chen, Y., Li, W., Zhang, C., Wu, Z., and Liu, J. (2020b). Recent developments of biomaterials for additive manufacturing of bone scaffolds. Adv. Healthc. Mater. 9:2000724. doi: 10.1002/adhm.202000724

Chen, Z., Yan, X., Yin, S., Liu, L., Liu, X., Zhao, G., et al. (2020a). Influence of the pore size and porosity of selective laser melted Ti6Al4V ELI porous scaffold on cell proliferation, osteogenesis and bone ingrowth. Mater. Sci. Eng. C. 106:110289. doi: 10.1016/j.msec.2019.110289

Cheng, A., Humayun, A., Cohen, D. J., Boyan, B. D., and Schwartz, Z. (2014). Additively manufactured $3 \mathrm{D}$ porous Ti-6Al-4V constructs mimic trabecular bone structure and regulate osteoblast proliferation, differentiation and local factor production in a porosity and surface roughness dependent manner. Biofabrication 6:045007. doi: 10.1088/1758-5082/6/4/045007

Chohan, J. S., Singh, R., Boparai, K. S., Penna, R., and Fraternali, F. (2017). Dimensional accuracy analysis of coupled fused deposition modeling and vapour smoothing operations for biomedical applications. Compos. Part B Eng. 117, 138-149. doi: 10.1016/j.compositesb.2017.02.045

Chua, C. M., Chua, C. K., Cheah, C. M., and Chua, S. W. (2003). Development of a tissue engineering scaffold structure library for rapid prototyping. Part 2: parametric library and assembly program. Adv. Manuf. Technol. 21, 303-312.

Cockerill, I., Su, Y., Sinha, S., Qin, Y. X., Zheng, Y., Young, M. L., et al. (2020). Porous zinc scaffolds for bone tissue engineering applications: a novel additive manufacturing and casting approach. Mater. Sci. Eng. C Mater. Biol. Appl. 110:110738. doi: 10.1016/j.msec.2020.110738

Cutolo, A., Engelen, B., Desmet, W., and Van Hooreweder, B. (2020). Mechanical properties of diamond lattice Ti-6Al-4V structures produced by laser powder bed fusion: on the effect of the load direction. J. Mech. Behav. Biomed. Mater. 104:103656. doi: 10.1016/j.jmbbm.2020.103656
Demir, A. G., and Previtali, B. (2017). Additive manufacturing of cardiovascular CoCr stents by selective laser melting. Mater. Des. 119, 338-350. doi: 10.1016/j. matdes.2017.01.091

Dias, M. R., Guedes, J. M., Flanagan, C. L., Hollister, S. J., and Fernandes, P. R. (2014). Optimization of scaffold design for bone tissue engineering: a computational and experimental study. Med. Eng. Phys. 36, 448-457. doi: 10. 1016/j.medengphy.2014.02.010

Dogan, E., Bhusal, A., Cecen, B., and Miri, A. K. (2020). 3D Printing metamaterials towards tissue engineering. Appl. Mater. Today 20:100752. doi: 10.1016/j.apmt. 2020.100752

Du, Y., Guo, J. L., Wang, J., Mikos, A. G., and Zhang, S. (2019). Hierarchically designed bone scaffolds: from internal cues to external stimuli. Biomaterials 218:119334. doi: 10.1016/j.biomaterials.2019.119334

Du, Y., Liang, H., Xie, D., Mao, N., Zhao, J., Tian, Z., et al. (2020). Design and statistical analysis of irregular porous scaffolds for orthopedic reconstruction based on voronoi tessellation and fabricated via selective laser melting (SLM). Mater. Chem. Phys. 239:121968. doi: 10.1016/j.matchemphys.2019. 121968

Fang, Z.-C., Wu, Z.-L., Huang, C.-G., and Wu, C.-W. (2020). Review on residual stress in selective laser melting additive manufacturing of alloy parts. Optics Laser Technol. 129:106283. doi: 10.1016/j.optlastec.2020.106283

Fantini, M., and Curto, M. (2017). Interactive design and manufacturing of a Voronoi-based biomimetic bone scaffold for morphological characterization. Int. J. Interact. Des. Manuf. 12, 585-596. doi: 10.1007/s12008-017-0416-x

Fantini, M., Curto, M., and De Crescenzio, F. (2016). A method to design biomimetic scaffolds for bone tissue engineering based on Voronoi lattices. Virtual Phys. Prototy. 11, 77-90. doi: 10.1080/17452759.2016.1172301

Feinberg, S., Hollister, S., Chu, T., and Halloran, J. (1999). An imagebased approach to design and manufacture of scaffolds for maxillofacial reconstruction. Maxillofacial Reconstruction 28:55. doi: 10.1016/S09015027(99)80817-0

Fu, J., Su, Y., Qin, Y.-X., Zheng, Y., Wang, Y., and Zhu, D. (2020). Evolution of metallic cardiovascular stent materials: a comparative study among stainless steel, magnesium and zinc. Biomaterials 230:119641. doi: 10.1016/j. biomaterials.2019.119641

Gibson, I., Rosen, D., and Stucker, B. (2015). Directed energy deposition processes. Addit. Manuf. Technol. 10, 245-268. doi: 10.1007/978-1-4939-2113-3_10

Gokuldoss, P. K., Kolla, S., and Eckert, J. (2017). Additive manufacturing processes: selective laser melting, electron beam melting and binder jetting-selection guidelines. Materials 10:672. doi: 10.3390/ma10060672

Gómez, S., Vlad, M. D., López, J., and Fernández, E. (2016). Design and properties of 3D scaffolds for bone tissue engineering. Acta Biomater. 42, 341-350. doi: 10.1016/j.actbio.2016.06.032

Gong, X., Anderson, T., and Chou, K. (2014). Review on powder-based electron beam additive manufacturing technology. Manuf. Rev. 1:2. doi: 10.1051/ mfreview/2014001

Goodridge, R. D., Tuck, C. J., and Hague, R. J. M. (2012). Laser sintering of polyamides and other polymers. Prog. Mater. Sci. 57, 229-267. doi: 10.1016/j. pmatsci.2011.04.001

Guo, Y., Chen, D., Cheng, M., Lu, W., Wang, L., and Zhang, X. (2013). The bone tissue compatibility of a new Ti35Nb2Ta3Zr alloy with a low Young's modulus. Int. J. Mol. Med. 31, 689-697. doi: 10.3892/ijmm.2013.1249

Habijan, T., Haberland, C., Meier, H., Frenzel, J., Wittsiepe, J., Wuwer, C., et al. (2013). The biocompatibility of dense and porous Nickel-Titanium produced by selective laser melting. Mater. Sci. Eng. C 33, 419-426. doi: 10.1016/j.msec. 2012.09.008

Hafeez, N., Liu, J., Wang, L., Wei, D., Tang, Y., Lu, W., et al. (2020). Superelastic response of low-modulus porous beta-type Ti-35Nb-2Ta-3Zr alloy fabricated by laser powder bed fusion. Addit. Manuf. 34:101264. doi: 10.1016/j.addma.2020. 101264

Han, C., Li, Y., Wang, Q., Wen, S., Wei, Q., Yan, C., et al. (2018). Continuous functionally graded porous titanium scaffolds manufactured by selective laser melting for bone implants. J. Mech. Behav. Biomed. Mater. 80, 119-127. doi: 10.1016/j.jmbbm.2018.01.013

He, J., Fang, J., Wei, P., Li, Y., Guo, H., Mei, Q., et al. (2021). Cancellous bone-like porous Fe@Zn scaffolds with core-shell-structured skeletons for biodegradable bone implants. Acta Biomater. 121, 665-681. doi: 10.1016/j.actbio.2020.11. 032 
Henkel, J., Woodruff, M. A., Epari, D. R., Steck, R., Glatt, V., Dickinson, I. C., et al. (2013). Bone regeneration based on tissue engineering conceptions - a 21st century perspective. Bone Res. 1, 216-248. doi: 10.4248/br201303002

Hollister, S. J. (2005). Porous scaffold design for tissue engineering. Nat. Mater. 4, 518-524. doi: 10.1038/nmat1421

Hooreweder, B. V., Lietaert, K., Neirinck, B., Lippiatt, N., and Wevers, M. (2017). CoCr F75 scaffolds produced by additive manufacturing: Influence of chemical etching on powder removal and mechanical performance. J. Mech. Behav. Biomed. Mater. 70, 60-67. doi: 10.1016/j.jmbbm.2017.03.017

Huang, S., Chen, Z., Pugno, N., Chen, Q., and Wang, W. (2014). A novel model for porous scaffold to match the mechanical anisotropy and the hierarchical structure of bone. Mater. Lett. 122, 315-319. doi: 10.1016/j.matlet.2014.02. 057

Jones, A. C., Arns, C. H., Sheppard, A. P., Hutmacher, D. W., Milthorpe, B. K., and Knackstedt, M. A. (2007). Assessment of bone ingrowth into porous biomaterials using MICRO-CT. Biomaterials 28, 2491-2504. doi: 10.1016/j. biomaterials.2007.01.046

Kapat, K., Srivas, P. K., Rameshbabu, A. P., Maity, P. P., Jana, S., Dutta, J., et al. (2017). Influence of porosity and pore-size distribution in Ti6Al4V foam on physicomechanical properties, osteogenesis, and quantitative validation of bone ingrowth by micro-computed tomography. ACS Appl. Mater. Inter. 9, 39235-39248. doi: 10.1021/acsami.7b13960

Kelly, C. N., Francovich, J., Julmi, S., Safranski, D., Guldberg, R. E., Maier, H. J., et al. (2019). Fatigue behavior of As-built selective laser melted titanium scaffolds with sheet-based gyroid microarchitecture for bone tissue engineering. Acta Biomater. 94, 610-626. doi: 10.1016/j.actbio.2019.05.046

Kopp, A., Derra, T., Müther, M., Jauer, L., Schleifenbaum, J. H., Voshage, M., et al. (2019). Influence of design and postprocessing parameters on the degradation behavior and mechanical properties of additively manufactured magnesium scaffolds. Acta Biomater. 98, 23-35. doi: 10.1016/j.actbio.2019.04.012

Kou, X. Y., and Tan, S. T. (2010). A simple and effective geometric representation for irregular porous structure modeling. Comput. Aided Des. 42, 930-941. doi: 10.1016/j.cad.2010.06.006

Lee, H., Lim, C. H. J., Low, M. J., Tham, N., Murukeshan, V. M., and Kim, Y.-J. (2017). Lasers in additive manufacturing: a review. Int. J. Pr. Eng. Man GT. 4, 307-322. doi: 10.1007/s40684-017-0037-7

Lei, H.-Y., Li, J.-R., Xu, Z.-J., and Wang, Q.-H. (2020). Parametric design of Voronoi-based lattice porous structures. Mater. Des. 191:108607. doi: 10.1016/ j.matdes.2020.108607

Li, J., Cui, X., Hooper, G. J., Lim, K. S., and Woodfield, T. B. F. (2020a). Rational design, bio-functionalization and biological performance of hybrid additive manufactured titanium implants for orthopaedic applications: a review. J. Mech. Behav. Biomed. Mater. 105:103671. doi: 10.1016/j.jmbbm.2020.103671

Li, Y., Jahr, H., Zhou, J., and Zadpoor, A. A. (2020b). Additively manufactured biodegradable porous metals. Acta Biomater. 115, 29-50. doi: 10.1016/j.actbio. 2020.08.018

Li, Y., Pavanram, P., Zhou, J., Lietaert, K., Taheri, P., Li, W., et al. (2020c). Additively manufactured biodegradable porous zinc. Acta Biomater. 101, 609623. doi: 10.1016/j.actbio.2019.10.034

Li, X., Li, D., and Zhang, Y. (2006). Investigation of bone tissue microstructure and indirect fabrication of biomimetic scaffold via stereolithography. Beijing Biomed. Eng. 25, 164-167.

Li, Y., Ding, Y., Munir, K., Lin, J., Brandt, M., Atrens, A., et al. (2019a). Novel $\beta$-Ti35Zr28Nb alloy scaffolds manufactured using selective laser melting for bone implant applications. Acta Biomater. 87, 273-284. doi: 10.1016/j.actbio. 2019.01.051

Li, Y., Jahr, H., Pavanram, P., Bobbert, F. S. L., Puggi, U., Zhang, X. Y., et al. (2019b). Additively manufactured functionally graded biodegradable porous iron. Acta Biomater. 96, 646-661. doi: 10.1016/j.actbio.2019.07.013

Li, Y., Zhou, J., Pavanram, P., Leeflang, M. A., Fockaert, L. I., Pouran, B., et al. (2018). Additively manufactured biodegradable porous magnesium. Acta Biomater. 67, 378-392. doi: 10.1016/j.actbio.2017.12.008

Liang, H., Zhao, D., Feng, X., Ma, L., Deng, X., Han, C., et al. (2020). 3D-printed porous titanium scaffolds incorporating niobium for high bone regeneration capacity. Mater. Des. 194:108890. doi: 10.1016/j.matdes.2020.108890

Limmahakhun, S., Oloyede, A., Sitthiseripratip, K., Xiao, Y., and Yan, C. (2017). 3D-printed cellular structures for bone biomimetic implants. Addit. Manuf. 15, 93-101. doi: 10.1016/j.addma.2017.03.010
Lin, Z., Wang, L., Xue, X., Lu, W., Qin, J., and Zhang, D. (2013). Microstructure evolution and mechanical properties of a Ti-35Nb-3Zr-2Ta biomedical alloy processed by equal channel angular pressing (ECAP). Mater. Sci. Eng. C. Mater. Biol. Appl. 33, 4551-4561. doi: 10.1016/j.msec.2013.07.010

Little, N., Rogers, B., and Flannery, M. (2011). Bone formation, remodelling and healing. Surgery 29, 141-145. doi: 10.1016/j.mpsur.2011.01.002

Liu, F., Mao, Z., Zhang, P., Zhang, D. Z., Jiang, J., and Ma, Z. (2018). Functionally graded porous scaffolds in multiple patterns: new design method, physical and mechanical properties. Mater. Des. 160, 849-860. doi: 10.1016/j.matdes.2018. 09.053

Liu, J., Liu, J., Attarilar, S., Wang, C., Tamaddon, M., Yang, C., et al. (2020). Nanomodifified titanium implant materials: a way toward improved antibacterial properties. Front. Bioeng. Biotechnol. 8:576969. doi: 10.3389/fbioe.2020.576969

Liu, S., Han, S., Wang, L., Liu, J., and Tang, H. (2019). Effects of Nb on the microstructure and compressive properties of an As-Cast Ni44Ti44Nb12 eutectic alloy. Materials 12:4118. doi: 10.3390/ma12244118

Liu, S., Han, S., Zhang, L., Chen, L., Wang, L., Zhang, L., et al. (2020). Strengthening mechanism and micropillar analysis of high-strength NiTi-Nb eutectic-type alloy prepared by laser powder bed fusion. Compos. Part B Eng. 200:108358. doi: 10.1016/j.compositesb.2020.108358

Liu, S., Liu, W., Liu, J., Zhang, L., Tang, Y., Zhang, L., et al. (2021). Compressive properties and microstructure evolution in NiTiNb alloy with mesh eutectic phase. Mater. Sci. Eng. A 801:140434. doi: 10.1016/j.msea

Liu, Y. J., Li, S. J., Wang, H. L., Hou, W. T., Hao, Y. L., Yang, R., et al. (2016). Microstructure, defects and mechanical behavior of beta-type titanium porous structures manufactured by electron beam melting and selective laser melting. Acta Mater. 113, 56-67. doi: 10.1016/j.actamat.2016.04.029

Luo, J. P., Huang, Y. J., Xu, J. Y., Sun, J. F., Dargusch, M. S., Hou, C. H., et al. (2020). Additively manufactured biomedical Ti-Nb-Ta-Zr lattices with tunable Young's modulus: mechanical property, biocompatibility, and proteomics analysis. Mater. Sci. Eng. C 114:110903. doi: 10.1016/j.msec.2020.110903

Lv, Y., Ding, Z., Sun, X., Li, L., Sha, G., Liu, R., et al. (2019). Gradient microstructures and mechanical properties of $\mathrm{Ti}-6 \mathrm{Al}-4 \mathrm{~V} / \mathrm{Zn}$ composite prepared by friction stir processing. Materials 12:2795.

Ma, N., Liu, S., Liu, W., Xie, L., Wei, D., Wang, L., et al. (2020). Research progress of titanium-based high entropy alloy: methods, properties, and applications. Front. Bioeng. Biotechnol. 8:603522. doi: 10.3389/fbioe.2020.603522

Ma, S., Song, K., Lan, J., and Ma, L. (2020a). Biological and mechanical property analysis for designed heterogeneous porous scaffolds based on the refined TPMS. J. Mech. Behav. Biomed. Mater. 107:103727. doi: 10.1016/j.jmbbm.2020. 103727

Ma, S., Tang, Q., Han, X., Feng, Q., Song, J., Setchi, R., et al. (2020b). Manufacturability, mechanical properties, mass-transport properties and biocompatibility of triply periodic minimal surface (TPMS) porous scaffolds fabricated by selective laser melting. Mater. Des. 195:109034. doi: 10.1016/j. matdes.2020.109034

Ma, S., Tang, Q., Feng, Q., Song, J., Han, X., and Guo, F. (2019). Mechanical behaviours and mass transport properties of bone-mimicking scaffolds consisted of gyroid structures manufactured using selective laser melting. J. Mech. Behav. Biomed. Mater. 93, 158-169. doi: 10.1016/j.jmbbm.2019.01.023

Maconachie, T., Leary, M., Lozanovski, B., Zhang, X., Qian, M., Faruque, O., et al. (2019). SLM lattice structures: properties, performance, applications and challenges. Mater. Des. 183:108137. doi: 10.1016/j.matdes.2019.108137

Marinela, P., Erick Ramírez-Cedillob, C., Adriana, H., and Hector, R. S. (2019). Structural design optimization of knee replacement implants for additive manufacturing. Procedia Manuf. 34, 574-583. doi: 10.1016/j.promfg.2019. 06.222

Mark, B., Mohamed, A., Yusuf, K., and Laurencina, C. T. (2002). Tissue engineered microsphere-based matrices for bone repair: design and evaluation. Biomaterials 23, 551-559.

Maskery, I., Hussey, A., Panesar, A., Aremu, A., Tuck, C., Ashcroft, I., et al. (2016). An investigation into reinforced and functionally graded lattice structures. $J$. Cell. Plast. 53, 151-165. doi: 10.1177/0021955x16639035

Mohamed, O. A., Masood, S. H., and Bhowmik, J. L. (2015). Optimization of fused deposition modeling process parameters: a review of current research and future prospects. Adv. Manuf. 3, 42-53. doi: 10.1007/s40436-014-0097-7

Moiduddin, K., Darwish, S., Al-Ahmari, A., ElWatidy, S., Mohammad, A., and Ameen, W. (2017). Structural and mechanical characterization of custom 
design cranial implant created using additive manufacturing. Electron. J. Biotechn. 29, 22-31. doi: 10.1016/j.ejbt.2017.06.005

Moravej, M., and Mantovani, D. (2011). Biodegradable metals for cardiovascular stent application: interests and new opportunities. Int. J. Mol. Sci. 12, 42504270. doi: $10.3390 /$ ijms 12074250

Motallebzadeh, A., Peighambardoust, N. S., and Sheikh, S. (2019). Microstructural, mechanical and electrochemical characterization of TiZrTaHfNb and Ti1.5ZrTa0.5Hf0.5 $\mathrm{Nb} 0.5$ refractory high-entropy alloys for biomedical applications. Intermetallics 113:106572. doi: 10.1016/j.intermet.2019. 106572

Murray, N. (2003). Microstructure evolution during solid-state foaming of titanium. Compos. Sci. Technol. 63, 2311-2316. doi: 10.1016/s0266-3538(03) 00264-1

Nagase, T., Iijima, Y., Matsugaki, A., Ameyama, K., and Nakano, T. (2019). Design and fabrication of Ti-Zr-Hf-Cr-Mo and Ti-Zr-Hf-Co-Cr-Mo high-entropy alloysas metallic biomaterials. J. Pre Proof 107:110322. doi: 10.1016/j.msec. 2019.110322

Nasrullah, A. I. H., Santosa, S. P., and Dirgantara, T. (2020). Design and optimization of crashworthy components based on lattice structure configuration. Structures 26, 969-981. doi: 10.1016/j.istruc.2020.05.001

Ngo, T. D., Kashani, A., Imbalzano, G., Nguyen, K. T. Q., and Hui, D. (2018). Additive manufacturing (3D printing): a review of materials, methods, applications and challenges. Compos. Part B Eng. 143, 172-196. doi: 10.1016/j. compositesb.2018.02.012

Onal, E., Frith, J., Jurg, M., Wu, X., and Molotnikov, A. (2018). Mechanical properties and in vitro behavior of additively manufactured and functionally graded Ti6Al4V porous scaffolds. Metals 8:200. doi: 10.3390/met8040200

Ouyang, P., Dong, H., He, X., Cai, X., Wang, Y., Li, J., et al. (2019). Hydromechanical mechanism behind the effect of pore size of porous titanium scaffolds on osteoblast response and bone ingrowth. Mater. Des. 183:108151. doi: $10.1016 /$ j.matdes.2019.108151

Park, J., Sutradhar, A., Shah, J. J., and Paulino, G. H. (2018). Design of complex bone internal structure using topology optimization with perimeter control. Comput. Biol. Med. 94, 74-84. doi: 10.1016/j.compbiomed.2018.01.001

Peng, W.-M., Liu, Y.-F., Jiang, X.-F., Dong, X.-T., Jun, J., Baur, D. A., et al. (2019). Bionic mechanical design and 3D printing of novel porous Ti6Al4V implants for biomedical applications. J. Zhejlang. Univ. Sci. B 20, 647-659. doi: 10.1631/jzus.B1800622

Podshivalov, L., Gomes, C. M., Zocca, A., Guenster, J., Bar-Yoseph, P., and Fischer, A. (2013). Design, analysis and additive manufacturing of porous structures for biocompatible micro-scale scaffolds. Procedia Cirp. 5, 247-252. doi: 10.1016/j. procir.2013.01.049

$\mathrm{Qu}, \mathrm{H}$. (2020). Additive manufacturing for bone tissue engineering scaffolds. Mater. Today Commun. 24:101024. doi: 10.1016/j.mtcomm.2020.101024

Radman, A., Huang, X., and Xie, Y. M. (2012). Topology optimization of functionally graded cellular materials. J. Mater. Sci. 48, 1503-1510. doi: 10.1007/ s10853-012-6905-1

Ran, Q., Yang, W., Hu, Y., Shen, X., Yu, Y., Xiang, Y., et al. (2018). Osteogenesis of 3D printed porous Ti6Al4V implants with different pore sizes. J. Mech. Behav. Biomed. Mater. 84, 1-11. doi: 10.1016/j.jmbbm.2018.04.010

Ren, D., Li, S., Wang, H., Hou, W., Hao, Y., Jin, W., et al. (2019). Fatigue behavior of Ti-6Al-4V cellular structures fabricated by additive manufacturing technique. J. Mater. Sci. Technol. 35, 285-294. doi: 10.1016/j.jmst.2018.09.066

Roseti, L., Parisi, V., Petretta, M., Cavallo, C., Desando, G., Bartolotti, I., et al. (2017). Scaffolds for bone tissue engineering: state of the art and new perspectives. Mater. Sci. Eng. C 78, 1246-1262. doi: 10.1016/j.msec.2017.05.017

Saint-Pastou Terrier, C., and Gasque, P. (2017). Bone responses in health and infectious diseases: a focus on osteoblasts. J. Infection 75, 281-292. doi: 10.1016/ j.jinf.2017.07.007

Shah, F. A., Omar, O., Suska, F., Snis, A., Matic, A., Emanuelsson, L., et al. (2016). Long-term osseointegration of 3D printed CoCr constructs with an interconnected open-pore architecture prepared by electron beam melting. Acta Biomater. 36, 296-309. doi: 10.1016/j.actbio.2016.03.033

Shor, L., Güçeri, S., Wen, X., Gandhi, M., and Sun, W. (2007). Fabrication of threedimensional polycaprolactone/hydroxyapatite tissue scaffolds and osteoblastscaffold interactions in vitro. Biomaterials 28, 5291-5297. doi: 10.1016/j. biomaterials.2007.08.018
Sing, S. L., Yeong, W. Y., and Wiria, F. E. (2016). Selective laser melting of titanium alloy with $50 \mathrm{wt} \%$ tantalum: microstructure and mechanical properties. J. Alloy. Compd. 660, 461-470. doi: 10.1016/j.jallcom.2015.11.141

Singh, R., Lee, P. D., Jones, J. R., Poologasundarampillai, G., Post, T., Lindley, T. C., et al. (2010). Hierarchically structured titanium foams for tissue scaffold applications. Acta Biomater. 6, 4596-4604. doi: 10.1016/j.actbio.2010.06.027

Song, G., and Song, S. (2007). A possible biodegradable magnesium implant material. Adv. Eng. Mater. 9, 298-302. doi: 10.1002/adem.200600252

Sood, A. K., Ohdar, R. K., and Mahapatra, S. S. (2010). Parametric appraisal of mechanical property of fused deposition modelling processed parts. Mater. Des. 31, 287-295. doi: 10.1016/j.matdes.2009.06.016

Speirs, M., Van Hooreweder, B., Van Humbeeck, J., and Kruth, J. P. (2017). Fatigue behaviour of NiTi shape memory alloy scaffolds produced by SLM, a unit cell design comparison. J. Mech. Behav. Biomed. Mater. 70, 53-59. doi: 10.1016/j. jmbbm.2017.01.016

Su, Y., Cockerill, I., Wang, Y., Qin, Y.-X., Chang, L., Zheng, Y., et al. (2019). Zinc-based biomaterials for regeneration and therapy. Trends Biotechnol. 37, 428-441. doi: 10.1016/j.tibtech.2018.10.009

Sun, W., Starly, B., Nam, J., and Darling, J. (2005). Bio-CAD modeling and its applications in computer-aided tissue engineering. Comput. Aided Des. 37, 1097-1114. doi: 10.1016/j.cad.2005.02.002

Surmeneva, M., Lapanje, A., Chudinova, E., Ivanova, A., Koptyug, A., Loza, K., et al. (2019). Decreased bacterial colonization of additively manufactured Ti6Al4V metallic scaffolds with immobilized silver and calcium phosphate nanoparticles. Appl. Surf. Sci. 480, 822-829. doi: 10.1016/j.apsusc.2019.03.003

Szymczyk-Ziółkowska, P., Łabowska, M. B., Detyna, J., Michalak, I., and Gruber, P. (2020). A review of fabrication polymer scaffolds for biomedical applications using additive manufacturing techniques. Biocybern. Biomed. Eng. 40, 624-638. doi: 10.1016/j.bbe.2020.01.015

Taniguchi, N., Fujibayashi, S., Takemoto, M., Sasaki, K., Otsuki, B., Nakamura, T., et al. (2016). Effect of pore size on bone ingrowth into porous titanium implants fabricated by additive manufacturing: an in vivo experiment. Mater. Sci. Eng. C 59, 690-701. doi: 10.1016/j.msec.2015.10.069

Tofail, S. A. M., Koumoulos, E. P., Bandyopadhyay, A., Bose, S., O’Donoghue, L., and Charitidis, C. (2018). Additive manufacturing: scientific and technological challenges, market uptake and opportunities. Mater. Today 21, 22-37. doi: 10.1016/j.mattod.2017.07.001

Wang, C., Huang, W., Zhou, Y., He, L., He, Z., Chen, Z., et al. (2020a). 3D printing of bone tissue engineering scaffolds. Bioact. Mater. 5, 82-91. doi: 10.1016/j. bioactmat.2020.01.004

Wang, S., Ding, Y., Yu, F., Zheng, Z., and Wang, Y. (2020b). Crushing behavior and deformation mechanism of additively manufactured Voronoi-based random open-cell polymer foams. Mater. Today Commun. 25:101406. doi: 10.1016/j. mtcomm.2020.101406

Wang, S., Shi, Z. A., Liu, L., Zhou, X., Zhu, L., and Hao, Y. (2020c). The design of Ti6Al4V Primitive surface structure with symmetrical gradient of pore size in biomimetic bone scaffold. Mater. Des. 193:108830. doi: 10.1016/j.matdes.2020. 108830

Wang, Y., Fu, P., Wang, N., Peng, L., Kang, B., Zeng, H., et al. (2020d). Challenges and solutions for the additive manufacturing of biodegradable magnesium implants. Engineering 6, 1267-1275. doi: 10.1016/j.eng.2020.02.015

Wang, H., Su, K., Su, L., Liang, P., Ji, P., and Wang, C. (2019). Comparison of 3D-printed porous tantalum and titanium scaffolds on osteointegration and osteogenesis. Mater. Sci. Eng. C 104:109908. doi: 10.1016/j.msec.2019.109908

Wang, S., Liu, L., Li, K., Zhu, L., Chen, J., and Hao, Y. (2019). Pore functionally graded Ti6Al4V scaffolds for bone tissue engineering application. Mater. Des. 168:107643. doi: 10.1016/j.matdes.2019.107643

Wang, L., Wang, C., Zhang, L. C., Chen, L., Lu, W., and Zhang, D. (2016). Phase transformation and deformation behavior of NiTi-Nb eutectic joined NiTi wires. Sci. Rep. 6:23905. doi: 10.1038/srep23905

Wang, X., Jiang, M., Zhou, Z., Gou, J., and Hui, D. (2017). 3D printing of polymer matrix composites: a review and prospective. Compos. Part B Eng. 110, 442-458. doi: 10.1016/j.compositesb.2016.11.034

Wang, X., Xu, S., Zhou, S., Xu, W., Leary, M., Choong, P., et al. (2016). Topological design and additive manufacturing of porous metals for bone scaffolds and orthopaedic implants: a review. Biomaterials 83, 127-141. doi: 10.1016/j. biomaterials.2016.01.012 
Wauthle, R., Ahmadi, S. M., Amin Yavari, S., Mulier, M., Zadpoor, A. A., Weinans, H., et al. (2015a). Revival of pure titanium for dynamically loaded porous implants using additive manufacturing. Mater. Sci. Eng. C 54, 94-100. doi: 10.1016/j.msec.2015.05.001

Wauthle, R., van der Stok, J., Amin Yavari, S., Van Humbeeck, J., Kruth, J.P., Zadpoor, A. A., et al. (2015b). Additively manufactured porous tantalum implants. Acta Biomater. 14, 217-225. doi: 10.1016/j.actbio.2014.12.003

Wettergreen, M. A., Bucklen, B. S., Starly, B., Yuksel, E., Sun, W., and Liebschner, M. A. K. (2005). Creation of a unit block library of architectures for use in assembled scaffold engineering. Comput. Aided Des. 37, 1141-1149. doi: 10. 1016/j.cad.2005.02.005

Xiao, D., Yang, Y., Su, X., Wang, D., and Sun, J. (2013). An integrated approach of topology optimized design and selective laser melting process for titanium implants materials. Bio Med. Mater. Eng. 23, 433-445. doi: 10.3233/bme130765

Xiao, D.-M., Yang, Y.-Q., Su, X.-B., Wang, D., and Luo, Z.-Y. (2012). Topology optimization of microstructure and selective laser melting fabrication for metallic biomaterial scaffolds. T. Nonferr. Metal. Soc. 22, 2554-2561. doi: 10. 1016/s1003-6326(11)61500-8

Xiao, F., and Yin, X. (2016). Geometry models of porous media based on Voronoi tessellations and their porosity-permeability relations. Comput. Math. Appl. 72, 328-348. doi: 10.1016/j.camwa.2015.09.009

Yamamoto, A., Kohyama, Y., Kuroda, D., and Hanawa, T. (2004). Cytocompatibility evaluation of Ni-free stainless steel manufactured by nitrogen adsorption treatment. Mater. Sci. Eng. C 24, 737-743. doi: 10.1016/j.msec.2004.08.017

Yan, C., Hao, L., Hussein, A., and Young, P. (2015). Ti-6Al-4V triply periodic minimal surface structures for bone implants fabricated via selective laser melting. J. Mech. Behav. Biomed. Mater. 51, 61-73. doi: 10.1016/j.jmbbm.2015. 06.024

Yan, C., Hao, L., Hussein, A., Young, P., and Raymont, D. (2014). Advanced lightweight 316L stainless steel cellular lattice structures fabricated via selective laser melting. Mater. Des. 55, 533-541. doi: 10.1016/j.matdes.2013.10.027

Yan, X., Li, Q., Yin, S., Chen, Z., Jenkins, R., Chen, C., et al. (2019). Mechanical and in vitro study of an isotropic Ti6Al4V lattice structure fabricated using selective laser melting. J. Alloy. Compd 782, 209-223. doi: 10.1016/j.jallcom.2018.12.220

Yang, N., Quan, Z., Zhang, D., and Tian, Y. (2014). Multi-morphology transition hybridization CAD design of minimal surface porous structures for use in tissue engineering. Comput. Aided Des. 56, 11-21. doi: 10.1016/j.cad.2014.06.006

Yang, N., Tian, Y., and Zhang, D. (2015). Novel real function based method to construct heterogeneous porous scaffolds and additive manufacturing for use in medical engineering. Med. Eng. Phys. 37, 1037-1046. doi: 10.1016/j.medengphy. 2015.08.006

Yang, N., and Zhou, K. (2014). Effective method for multi-scale gradient porous scaffold design and fabrication. Mater. Sci. Eng. C 43, 502-505. doi: 10.1016/j. msec.2014.07.052

Yang, X. Y., Huang, X., Rong, J. H., and Xie, Y. M. (2013). Design of 3D orthotropic materials with prescribed ratios for effective Young's moduli. Comp. Mater. Sci. 67, 229-237. doi: 10.1016/j.commatsci.2012.08.043

Yang, Z., Gu, H., Sha, G., Lu, W., Yu, W., Zhang, W., et al. (2018). TC4/Ag metal matrix nanocomposites modified by friction stir processing: surface characterization, antibacterial property, and cytotoxicity in vitro. ACS App.l Mater. Interfaces 10, 41155-41166. doi: 10.1021/acsami.8b16343

Yoo, D.-J. (2011a). Three-dimensional surface reconstruction of human bone using a -spline based interpolation approach. Comput. Aided Des. 43, 934-947. doi: 10.1016/j.cad.2011.03.002

Yoo, D. J. (2011b). Porous scaffold design using the distance field and triply periodic minimal surface models. Biomaterials 32, 7741-7754. doi: 10.1016/j. biomaterials.2011.07.019

Yu, S., Sun, J., and Bai, J. (2019). Investigation of functionally graded TPMS structures fabricated by additive manufacturing. Mater. Des. 182:108021. doi: 10.1016/j.matdes.2019.108021

Yuan, L., Ding, S., and Wen, C. (2019). Additive manufacturing technology for porous metal implant applications and triple minimal surface structures: a review. Bioact. Mater. 4, 56-70. doi: 10.1016/j.bioactmat.2018.12.003
Zadpoor, A. A. (2019). Mechanical performance of additively manufactured meta-biomaterials. Acta Biomater. 85, 41-59. doi: 10.1016/j.actbio.2018.12. 038

Zhang, L., Song, B., Fu, J. J., Wei, S. S., Yang, L., Yan, C. Z., et al. (2020). Topology-optimized lattice structures with simultaneously high stiffness and light weight fabricated by selective laser melting: design, manufacturing and characterization. J. Manuf. Porcess 56, 1166-1177. doi: 10.1016/j.jmapro.2020. 06.005

Zhang, X.-Y., Fang, G., Leeflang, S., Zadpoor, A. A., and Zhou, J. (2019). Topological design, permeability and mechanical behavior of additively manufactured functionally graded porous metallic biomaterials. Acta Biomater. 84, 437-452. doi: 10.1016/j.actbio.2018.12.013

Zhang, X.-Y., Yan, X.-C., Fang, G., and Liu, M. (2020). Biomechanical influence of structural variation strategies on functionally graded scaffolds constructed with triply periodic minimal surface. Addit. Manuf. 32:101015. doi: 10.1016/j.addma. 2019.101015

Zhang, X. Z., Leary, M., Tang, H. P., Song, T., and Qian, M. (2018). Selective electron beam manufactured Ti-6Al-4V lattice structures for orthopedic implant applications: current status and outstanding challenges. Curr. Opin. Solid St. M. 22, 75-99. doi: 10.1016/j.cossms.2018.05.002

Zhao, D., Han, C., Li, Y., Li, J., Zhou, K., Wei, Q., et al. (2019). Improvement on mechanical properties and corrosion resistance of titanium-tantalum alloys in-situ fabricated via selective laser melting. J. Alloy. Compd. 804, 288-298. doi: 10.1016/j.jallcom.2019.06.307

Zhao, L., Ha, S., Sharp, K. W., Geltmacher, A. B., Fonda, R. W., Kinsey, A. H., et al. (2014). Permeability measurements and modeling of topology-optimized metallic 3-D woven lattices. Acta Mater. 81, 326-336. doi: 10.1016/j.actamat. 2014.08.037

Zhao, S., Hou, W. T., Xu, Q. S., Li, S. J., Hao, Y. L., and Yang, R. (2018). “Ti$6 \mathrm{Al}-4 \mathrm{~V}$ lattice structures fabricated by electron beam melting for biomedical applications," in Titanium in Medical and Dental Applications, eds F. Froes, and M. Qian (Cambridge: Woodhead Publishing), 277-301. doi: 10.1016/b978-012-812456-7.00013-5

Zheng, S., Li, J., Jing, X., and Gong, Z. (2020). Parameterized design and fabrication of porous bone scaffolds for the repair of cranial defects. Med. Eng. Phys. 81, 39-46. doi: 10.1016/j.medengphy.2020.05.002

Zhou, C., Deng, C., Chen, X., Zhao, X., Chen, Y., Fan, Y., et al. (2015). Mechanical and biological properties of the micro-/nano-grain functionally graded hydroxyapatite bioceramics for bone tissue engineering. J. Mech. Behav. Biomed. Mater. 48, 1-11. doi: 10.1016/j.jmbbm.2015. 04.002

Zhou, H., Zhao, M., Ma, Z., Zhang, D. Z., and Fu, G. (2020). Sheet and network based functionally graded lattice structures manufactured by selective laser melting: design, mechanical properties, and simulation. Int. J. Mech. Sci. 175:105480. doi: 10.1016/j.ijmecsci.2020.105480

Zhu, C., Lv, Y., Qian, C., Ding, Z., Jiao, T., Gu, X., et al. (2018). Microstructures, mechanical, and biological properties of a novel Ti-6V-4V/zinc surface nanocomposite prepared by friction stir processing. Int. J. Nanomed. 13, 18811898. doi: $10.2147 /$ IJN.S154260

Zhu, C., Lv, Y., Qian, C., Qian, H., Jiao, T., Wang, L., et al. (2016). Proliferation and osteogenic differentiation of rat BMSCs on a novel Ti/SiC metal matrix nanocomposite modified by friction stir processing. Sci. Rep. 6:38875. doi: 10. 1038/srep38875

Conflict of Interest: The authors declare that the research was conducted in the absence of any commercial or financial relationships that could be construed as a potential conflict of interest.

Copyright $\odot 2021 \mathrm{Lv}$, Wang, Liu, Tang, Lu, Xie, Lan, Liu, Qin and Wang. This is an open-access article distributed under the terms of the Creative Commons Attribution License (CC BY). The use, distribution or reproduction in other forums is permitted, provided the original author(s) and the copyright owner(s) are credited and that the original publication in this journal is cited, in accordance with accepted academic practice. No use, distribution or reproduction is permitted which does not comply with these terms. 